\title{
Alteration of ultrasonic signatures by stress-induced changes in hydro-mechanical properties of fractured rocks
}

\author{
Arash Kamali-Asl $^{\mathrm{a}, *}$, Bijay KC ${ }^{\mathrm{b}}$, Ehsan Ghazanfari ${ }^{\mathrm{c}}$, Ismael Himar Falcon-Suarez ${ }^{\mathrm{d}}$ \\ ${ }^{\text {a }}$ Post-Doctoral Fellow, Department of Geophysics, Stanford University, Stanford, CA, USA \\ ${ }^{\mathrm{b}}$ PhD Student, Department of Civil and Environmental Engineering, University of Vermont, Burlington, VT, USA \\ ${ }^{\mathrm{c}}$ Associate Professor, Department of Civil and Environmental Engineering, University of Vermont, Burlington, VT, USA \\ ${ }^{\mathrm{d}}$ Research Fellow, National Oceanography Centre, University of Southampton Waterfront Campus, Southampton, United Kingdom
}

\section{A R T I C L E I N F O}

\section{Keywords:}

Ultrasonic signatures

Permeability

Fracture aperture

Time-frequency map

Time-dependent fracture displacement

\begin{abstract}
A B S T R A C T
In this study, we evaluate the changes in ultrasonic signatures (i.e., frequency content, velocity, amplitude, and attenuation) due to stress-induced alteration of fracture aperture/permeability. Flow-through experiments were performed on artificially-fractured phyllite specimens along with the concurrent measurements of ultrasonic signatures under different stress conditions. Increasing pore pressure led to fracture opening, as indicated by increases in both mechanical and hydraulic apertures. In addition, we observed that increase in confining pressure (and decrease in pore pressure) led to increases in ultrasonic velocities, ultrasonic amplitudes, and fracture specific stiffness, and decrease in ultrasonic attenuations. It was found that time-frequency partitioning depends on hydraulic aperture. The higher frequency band, for both P- and S-waves, was insensitive to the changes in stress conditions; the lower band was sensitive to the changes in stress conditions, as long as the hydraulic aperture was changing. Three-Element rheological and Power-Law models successfully predicted the time-dependent fracture displacement, with the former being more accurate at higher levels of pore pressures.
\end{abstract}

\section{Introduction}

In geo-resources, the characterization of fracture network is crucial to understand and predict the reservoir behavior during both (re)stimulation and long-term production stages. ${ }^{1}$ Coupled thermo-hydro-mechanical-chemical (THMC) processes can affect their response, ${ }^{2,3}$ which includes pressure solution caused by high stress concentrations at asperities in-contact, ${ }^{4,5}$ mineral dissolution/precipitation, ${ }^{6,7}$ mechanical creep, ${ }^{8}$ hydraulic fracturing, ${ }^{9}$ and shear/slip along fractures/faults. ${ }^{10}$ For instance, in geothermal reservoirs, the temperature-assisted chemical dissolution/precipitation processes contribute to reducing the permeability. ${ }^{11}$ Additionally, in shale gas formations, hydraulic fractures are prone to closure during production stage, ${ }^{12}$ caused by pore pressure reduction ${ }^{13,14}$ and mechanical creep. $^{8,15}$

Geophysical signals can propagate long distances and reveal information about a fractured formation. ${ }^{16}$ In particular, the alteration of the flow characteristics in fractured formations can be monitored using seismic waves as high-resolution probes, sensitive to different geological conditions such as temperature, overburden and pore pressures, saturation level, and depth of interest. ${ }^{16-19}$ As seismic waves propagate through a fractured medium, frequency-dependent elastic interface waves are generated, which are categorized into fast and slow interface waves with velocities ranging from shear-wave (upper limit) to Rayleigh-wave (lower limit). ${ }^{20-23}$ While the energy of these interface waves depends on stress states and fracture geometry, ${ }^{21,24}$ a direct relationship exists between fracture-specific stiffness and propagation of interface waves. ${ }^{25,26}$ Hence, seismic response of fractured formations is substantially affected by both alteration of hydraulic and mechanical properties. ${ }^{25,27,28}$ In this regard, geochemical processes at the fracture surface might weaken/strengthen the fracture shearing behavior, which in turn, might affect the outcome of hydro-shearing process. ${ }^{16}$ Therefore, fracture aperture/permeability dependencies and evolution can be potentially assessed and monitored using remote sensing tools (i.e., seismic signatures).

In this study, the sensitivity of ultrasonic signatures to stress-induced changes in hydraulic/mechanical properties of fractured reservoirs analogues were experimentally investigated. To this aim, ultrasonic P- and cross-polarized S-waves velocities, amplitudes, attenuations, and timefrequency content were analyzed together with mechanical

\footnotetext{
* Corresponding author.

E-mail address: akamalia@stanford.edu (A. Kamali-Asl).
} 
a)

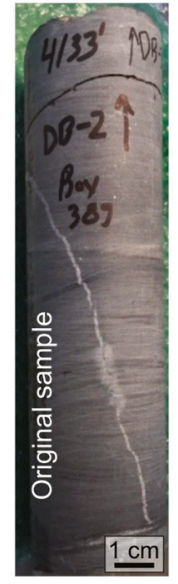

b)

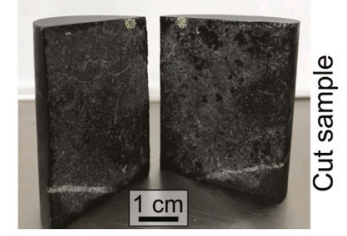

c)

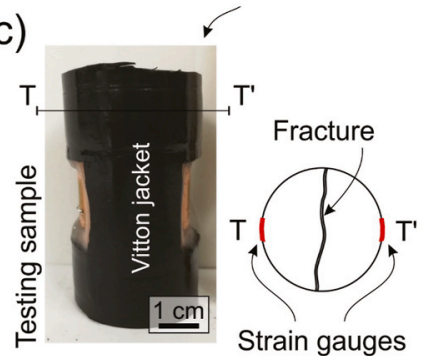

d)

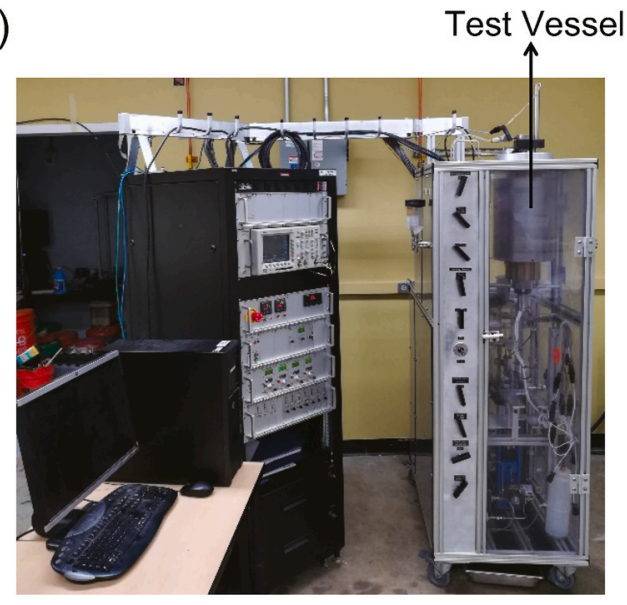

e)

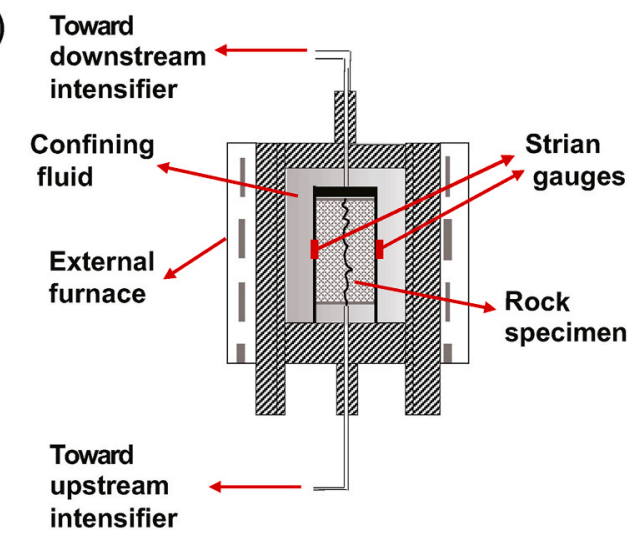

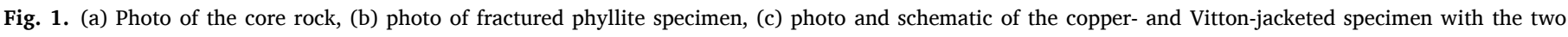

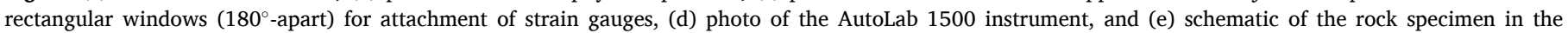
test vessel.

Table 1

Samples properties.

\begin{tabular}{|c|c|c|c|c|c|c|c|c|}
\hline \multirow[t]{2}{*}{ Sample } & \multirow{2}{*}{$\frac{\mathrm{L}}{\mathrm{Mm}}$} & \multirow{2}{*}{$\frac{\mathrm{D}}{\mathrm{Cm}}$} & \multirow{2}{*}{$\frac{\rho_{\mathrm{d}}}{\mathrm{kg} \cdot \mathrm{m}^{-3}}$} & \multirow{2}{*}{$\frac{\varphi}{\%}$} & \multicolumn{4}{|c|}{ *XRD-Mineralogy (\%) } \\
\hline & & & & & Quartz & Albite & Biotite & Chlorite \\
\hline PL1 & 47 & 38 & 2690 & 0.74 & 67.4 & 18.8 & 10.5 & 3.2 \\
\hline PL2 & 49 & & & & & & & \\
\hline
\end{tabular}

deformation and permeability changes in a fractured sample under variable stress states conditions. We studied the effects of changes in pore and confining pressures on ultrasonic signatures, caused by changes in hydraulic/mechanical properties of the fracture. Subsequently, correlations between pore pressure and ultrasonic signatures were developed. In addition, alterations in amplitude and frequency partitioning of time-frequency maps due to changes in hydromechanical properties of fracture were investigated.

\section{Materials and methods}

\subsection{Rock sample preparation}

A phyllite rock core (shown in Fig. 1(a)), collected from DB-2 well (depth of $1260 \mathrm{~m}$ ) at the Blue Mountain geothermal field (Nevada, USA), was sub-cored in vertical and horizontal directions to create two $38-\mathrm{mm}$ diameter rock plugs (PL1 and PL2 with lengths of 47 and $49 \mathrm{~mm}$, respectively; see samples properties and composition in Table 1 ).

A modified Brazilian test ${ }^{29}$ was conducted to induce a longitudinal tensile fracture in the samples (Fig. 1(b)). Before performing the test, the samples were saturated in deionized water (DIW) via water imbibition in a vacuum vessel..$^{30}$ The two halves of the saturated fractured specimens were mated together. Both specimens were then put inside a sleeve jacket before being placed in the core-holders for flow-through experiments. For PL2, the specimen was first wrapped in copper jacket, to which two sets of axial and radial strain gauges were attached. In addition, two small openings ( $180^{\circ}$ apart), as shown in Fig. 1(c), were cut on the Viton jacket of PL2 specimen to be able to connect the soldered wires from the strain gauges to the base plug. Note that the axial and radial strain gauges were attached only on PL2 specimen.

\subsection{Experimental procedure}

For the tests, we used a high-pressure/temperature fully servocontrolled triaxial AutoLab 1500 system (New England Research; Fig. 1(d)). This system is capable of applying hydrostatic confining stress and pore pressures of up to $70 \mathrm{MPa}$ (but a deviatoric stress of up to 580 $\mathrm{MPa}$ ), and a vessel temperature of $130^{\circ} \mathrm{C}$. The pore pressure intensifiers 
a)

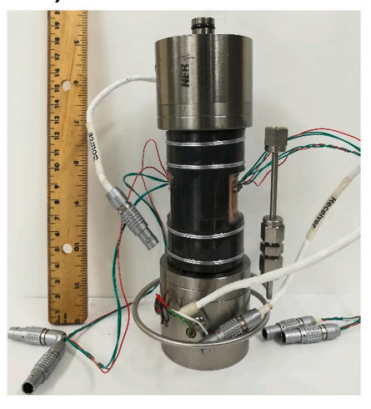

b)

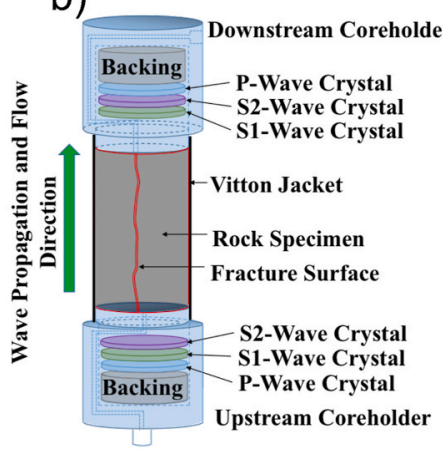

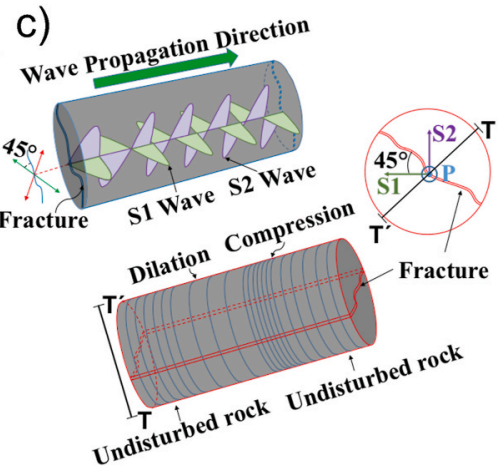

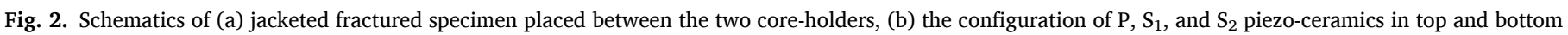
core-holders, and (c) direction of propagation of $\mathrm{P}_{-}, \mathrm{S}_{1^{-}}$, and $\mathrm{S}_{2^{-}}$waves in the fractured specimen.

are also equipped with linear variable differential transformers (LVDTs) that allow continuous monitoring of the volume change in the intensifiers. Using this setup, we conducted a pressure-controlled test (PCT) with a precision of $\pm 0.1 \mathrm{MPa}$ and a displacement-controlled test (DCT) with an error of $\pm 0.2 \%$ over the flow rate range, with DIW at a temperature of $25{ }^{\circ} \mathrm{C}$. During the experiments, ultrasonic P-wave and cross-polarized S-waves were collected every $0.5 \mathrm{~h}$. The two orthogonal components are named S1 and S2. The fracture plane in both samples was oriented at $\sim 45^{\circ}$ to the S1-waves propagation plane (Fig. 2). In addition, to assess the particular effect of the saturated fracture on the ultrasonic properties, the ultrasonic attributes were also measured on a third intact (non-fractured) phyllite sample (with same dimensions as PL1) under $\mathrm{P}_{\mathrm{c}}=15 \mathrm{MPa}$.

\subsection{Data processing techniques}

ASTM D5777 Standard ${ }^{31}$ was used to manually pick the arrival time of ultrasonic waves, which were then used for estimation of P- and $\mathrm{S}$-waves velocities $\left(\mathrm{V}_{\mathrm{P}}, \mathrm{V}_{\mathrm{S} 1}\right.$, and $\left.\mathrm{V}_{\mathrm{S} 2}\right)$. In addition to velocities, the amplitudes, attenuations, and time-frequency analysis provide indications of the change in ultrasonic properties. ${ }^{25,27,32}$ The amplitude of first-peak in time-domain for P- and cross-polarized S-waves at each of the recording points (i.e., each half-an-hour) throughout flow-through experiments were recorded and normalized with respect to their first value. The attenuation analysis for the fractured samples was performed following the procedure outlined by Pyrak-Nolte et al., ${ }^{21}$ as expressed in Eq. (1):

$Q=-\pi f x /\left[\operatorname{cln}\left(A / A_{l}\right)\right]$

where, $\mathrm{Q}$ is the ultrasonic quality factor, $\mathrm{f}$ is the central frequency of the transmitted ultrasonic wave, $x$ is the length of the specimen (i.e. fractured rock), $\mathrm{c}$ is the phase velocity of the ultrasonic wave, and A and $A_{1}$ are the maximum spectral amplitudes of the fractured rock and an aluminum specimen (with identical dimensions as fractured rock specimen), respectively. Fourier transform was performed to estimate the maximum spectral amplitude of the ultrasonic waves at each time instance, using continuous wavelet transform (CWT) to decompose time-domain signals into time-frequency maps. ${ }^{33-36}$

Morlet mother wavelet $^{37}$ was implemented to generate time-frequency maps of P- and S-waves at representative points. We used the built-in Wavelet Toolbox in MATLAB software to obtain the time-frequency maps. These maps reveal some of the characteristics of ultrasonic waves at different states-of-stress, ${ }^{32}$ including maximum spectral amplitude, dominant frequencies, and time-frequency partitioning, with the latter considered as the proportion of the energy conserved in different parts of the time-frequency maps.

Based on the Darcy's law, the permeability could be estimated using the pore pressures measured in the experiments as:
$k=\frac{Q \mu L}{A \Delta P}$

where $Q$ is the flow rate $\left(\mathrm{m}^{3} / \mathrm{s}\right), \mu$ is the dynamic viscosity of the fluid (Pa.s), L is the length of the specimen (m), A is the cross-section area of the specimen $\left(\mathrm{m}^{2}\right)$, and $\Delta \mathrm{P}$ is the differential pore pressure across the two ends of the specimen $(\mathrm{Pa})$.

Since the specimens had very low porosity $(\sim 1 \%$; see Table 1$)$, with impermeable matrix, the modified cubic law with parallel plate approximation was used to evaluate the hydraulic aperture expressed $\mathrm{as}^{38}$ :

$b=\sqrt[3]{\frac{12 \mu L Q}{\Delta P . D}}$

where $b$ is the hydraulic aperture $(m)$, and $D$ is the diameter of the specimen (m).

\subsection{Experimental program}

Cubic law relationship, as presented in Eq. (3), gives an estimation of fracture aperture based on the hydraulic energy induced by the flow rate and (differential) pore pressure, and thus is referred to as hydraulic aperture $\left(b_{h}\right)$. On the other hand, we refer to mechanical aperture $\left(b_{m}\right)$ when considering the sole effect of the confining stress, and it is related to the geometric distance between the asperities in the two halves of the fractured specimen. When the initial aperture is less than $\sim 10 \mu \mathrm{m}$, the ratio of the change in mechanical aperture to the change in hydraulic aperture (i.e., $\frac{\Delta b_{m}}{\Delta b_{h}}$ ), due to a physical perturbation such as change in effective stress, varies between 10 and 20. This difference between mechanical and hydraulic apertures could be attributed to fracture roughness and tortuosity, particularly when the aperture size is small. $^{39,40}$

TThe PCT and DCT tests were designed to isolate the analysis of hydraulic and mechanical apertures, respectively. We conducted a PCT on PL1, and a DCT on PL2 to investigate the effects of confining pressure $\left(\mathrm{P}_{\mathrm{c}}\right)$ and pore pressures $\left(\mathrm{P}_{\mathrm{P}}\right)$ on fracture response and wave propagation through fracture. For the PCT, the differential pore pressure $\left(\Delta \mathrm{P}_{\mathrm{p}}=\mathrm{P}_{\text {up }}\right.$ $\mathrm{P}_{\text {down }}$ ) was set as the controlled parameter, while the evolution of the outflow rate was recorded and used to estimate the corresponding fracture aperture/permeability during the test. In the case of DCT, the injection flow rate was set to $2.65 \times 10^{-11} \mathrm{~m}^{3} / \mathrm{s}$ and $\mathrm{P}_{\text {down }}$ was set constant, while $\mathrm{P}_{\text {up }}$ was the monitoring parameter. The evolution of $\Delta \mathrm{P}_{\mathrm{p}}$ was used to estimate fracture aperture/permeability.

In both DCT and PCT, the mechanical aperture is altered when the effective stress changes, as it is intuitive that the geometric distance between asperities would depend on effective stress. The hydraulic aperture is, however, more complex and reacts differently in DCT and PCT. In DCT, the rate of injected volume (i.e., flow rate) into the sample 
Table 2

Summary of the experiments.

\begin{tabular}{llll}
\hline $\begin{array}{l}\text { Experiment } \\
\text { Type }\end{array}$ & $\begin{array}{l}\text { Confining } \\
\text { Pressure (MPa) }\end{array}$ & Pore Pressure (MPa) & Resulting Parameters \\
\hline DCT & 60 & {$[1,10,20,30,40]$} & $\begin{array}{l}\text { Ultrasonic } \\
\text { signatures, fracture- } \\
\text { specific stiffness, } \\
\text { mechanical } \\
\text { deformation }\end{array}$ \\
& & & $\begin{array}{l}\text { Ultrasonic } \\
\text { signatures, fracture- } \\
\text { specific stiffness, } \\
\text { hydraulic aperture }\end{array}$ \\
PCT & {$[15,30,45,30,15]$} & {$[5.5,11,16.5,11,5.5]$} & \\
& & &
\end{tabular}

is constant, and hence, the volume that is available for fluid flow (hereafter referred as fractured volume) should remain constant throughout the experiment. Therefore, when the hydraulic aperture starts to change, as a result of change in effective stress, the differential pore pressure is automatically adjusted to maintain the constant flow rate. Consequently, the fractured volume does not change, which dictates constant hydraulic aperture. Therefore, displacement-controlled tests (i.e., DCTs) are only an experimental trick to estimate fracture aperture. On the other hand, in PCT the differential pore pressure is constant. A change in flow rate, due to a change in effective stress, results in a change in fractured volume. Consequently, the hydraulic aperture would change, as the ability of fracture to transport fluid would change. In short, the hydraulic aperture is constant in DCT, while it is not constant in PCT.

A summary of the experimental conditions is presented in Table 2. Fig. 3 shows the stress paths used in the DCT and PCT. For the DCT, deviatoric stress was set to $\sigma_{\mathrm{dev}}=6 \mathrm{MPa}$, with $\mathrm{P}_{\mathrm{c}}=60 \mathrm{MPa}$, while $\mathrm{P}_{\text {down }}$ was stepwise increased $10 \mathrm{MPa}$ ( $9 \mathrm{MPa}$ for the first step) from 1 to 40 MPa. Each step of the stress path was held constant for $24 \mathrm{~h}$. For the PCT, hydrostatic confining conditions were applied to simulate overburden and pore pressures equivalent to 630,1260 , and $1890 \mathrm{~m}$ depth, by adopting 24.1 and $8.8 \mathrm{MPa} / \mathrm{km}$ rates for $\mathrm{P}_{\mathrm{c}}$ and $\mathrm{P}_{\mathrm{p}}$, respectively. The stress path for this test is comprised of 10 stages. We determined the optimal upstream pore pressure, at each stage, by trial and error so that the flow rate in consecutive stages is not too low or too high. This way, we had $1 \mathrm{~cm}^{3}(\sim 5 \%)$ of fluid in the upstream pore pressure intensifier at the end of the experiment. As it can be seen in Fig. 3(b), there is an $\sim 8 \mathrm{~h}$ delay between variations of $\mathrm{P}_{\mathrm{p}}$ and $\mathrm{P}_{\mathrm{c}}$. This delay was considered in the design of stress path in order to (i) distinguish the effects of each stress component on the evolution of fracture aperture, and (ii) evaluate the influence of the effective stress (i.e., $\mathrm{P}_{\mathrm{c}}-\mathrm{P}_{\mathrm{p}}$ ) on the ultrasonic properties. In addition, the stress path for the PCT was designed to capture the effects of stress corrosion at higher effective stresses. Stress corrosion is defined as sub-critical crack growth due to a sudden change in the environment of crack/fracture, such as an abrupt change in loading, in the presence of water or at high temperatures. ${ }^{41}$ From a micro-scale approach, subcritical crack growth is caused by stress concentration at the fracture tip (i.e., fracture asperities), resulting in tensile failure of these asperities. From a macro-scale approach, however, the subcritical

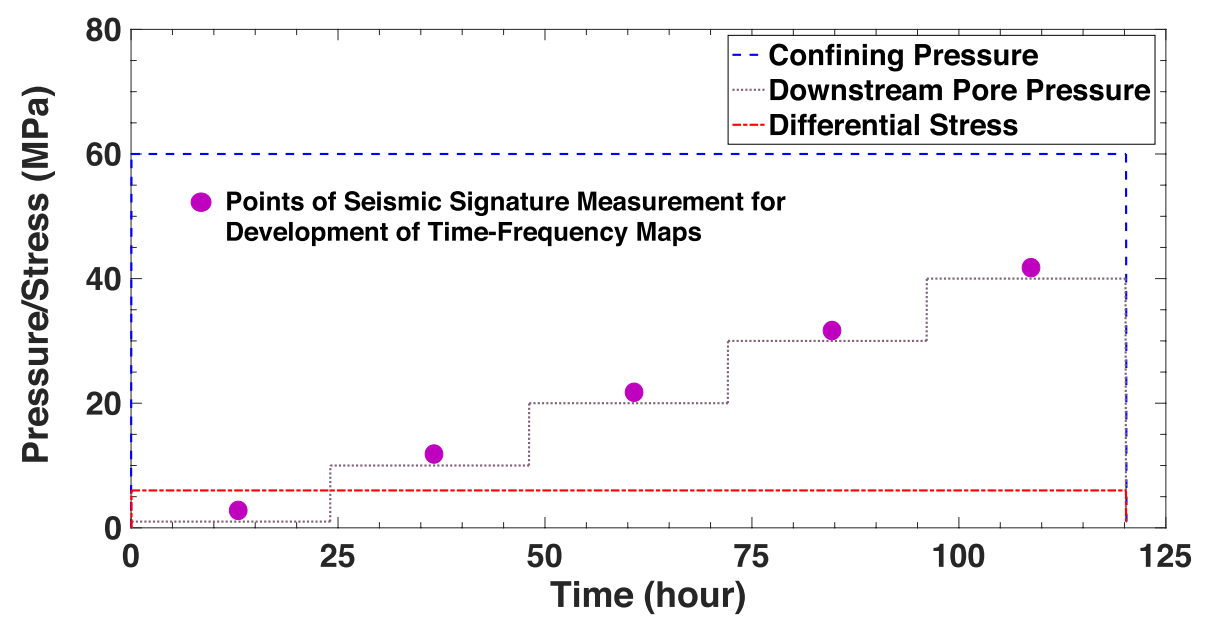

(a)

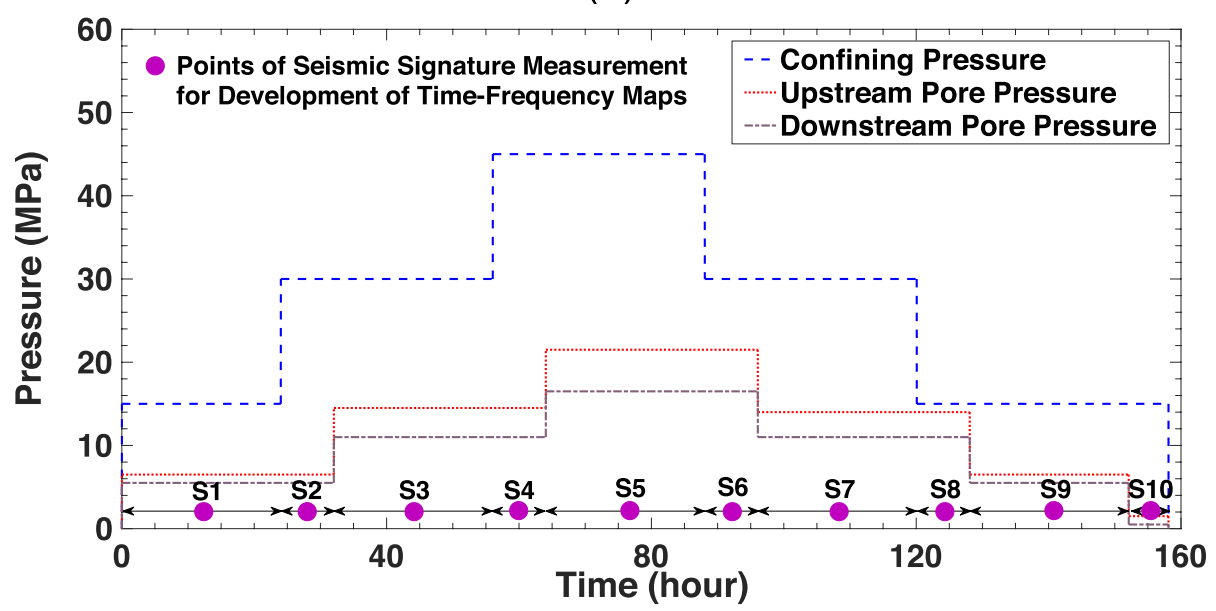

(b)

Fig. 3. Stress path followed in the (a) DCT and (b) PCT. 


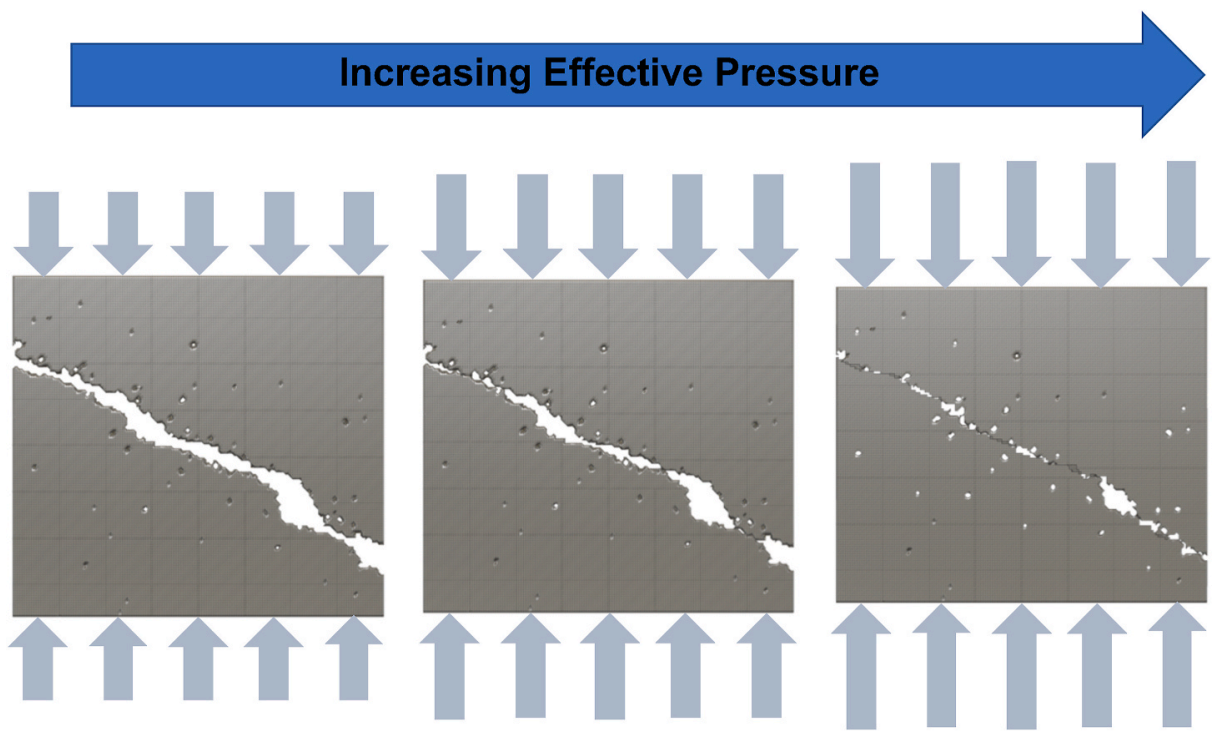

Fig. 4. Schematic of the concept of stress corrosion.

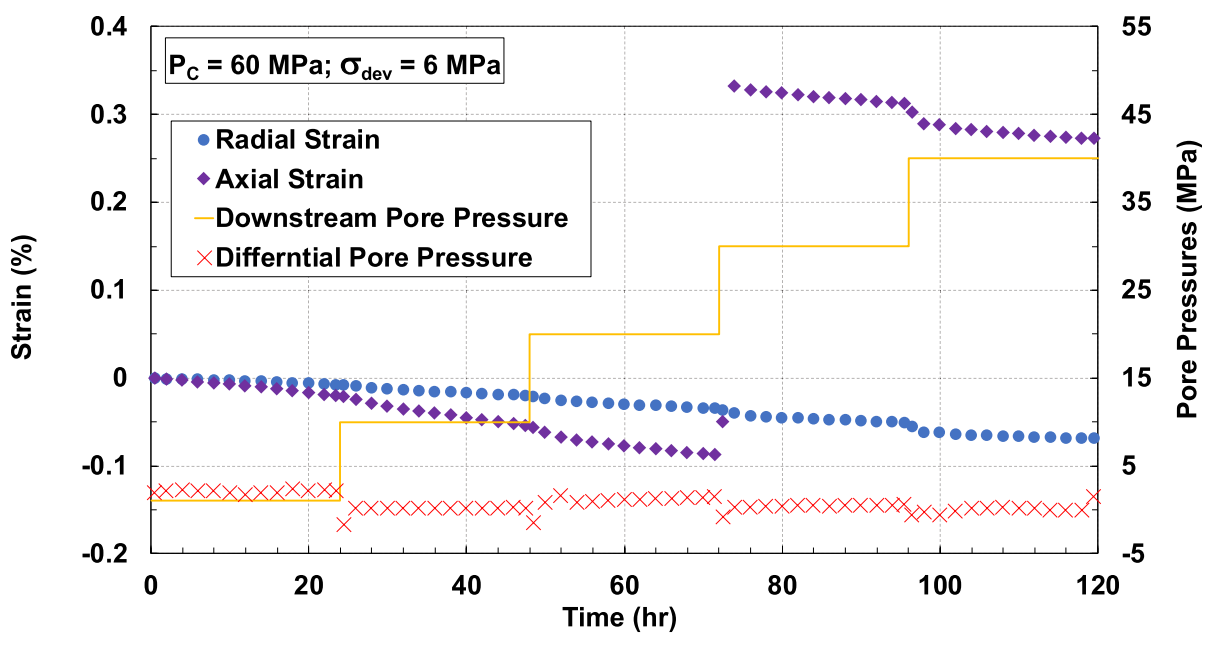

Fig. 5. Evolutions of axial and radial strain data at different stages of the DCT.

crack growth leads to enhanced compaction, resulted from increased contact-area, which in turn, reduces fracture aperture when effective stress increases, as shown in Fig. 4.

The evolutions of radial strains, differential pore pressure (in DCT), and outflow rate (in PCT) were recorded every second during the tests, while ultrasonic responses were collected every $0.5 \mathrm{~h}$. For better clarity, all data were binned to every $2 \mathrm{~h}$.

\section{Test results}

\subsection{Displacement controlled test (DCT)}

Fig. 5 shows the time evolutions of average axial and radial strains along with differential pore pressure at different stages of DCT. Within each stage of the test, $P_{\text {down }}$ is held constant, $P_{\text {up }}$ is automatically adjusted (in most cases increases) by the instrument to maintain the constant injection rate. This would result in a constant hydraulic aperture, while mechanical aperture varies.

Within each stage of constant $\mathrm{P}_{\text {down }}$, an increase in the upstream pore pressure (and consequently increase in differential pore pressure) leads to a continuous increase in the mechanical aperture of the fracture. This inflation is reflected in a gradual decrease of radial strain (Fig. 5). In addition, when transitioning from one $\mathrm{P}_{\text {down }}$ stage to the next, there is a sudden decrease in radial strain, caused by a sudden increase in mechanical aperture, as also observed by Nooraeipour et al. ${ }^{42}$ Note that negative $\Delta \mathrm{P}_{\mathrm{p}}$ values are related to the delay in the servo-controller response (i.e., $\mathrm{P}_{\mathrm{up}}$ readjustment) in constant injection rate mode, with respect to pressure sensor downstream $\left(\mathrm{P}_{\text {down }}\right)$. The gradual increase of radial strain within each stage and the sudden increase of radial strain with $\mathrm{P}_{\text {down }}$ changes are more significant at higher $\mathrm{P}_{\text {down }}$ values. Also, $\Delta \mathrm{Pp}$ is decreasing with the increasing $\mathrm{P}_{\text {down }}$, indicating permeability is increasing with pore pressure. This observation is in agreement with the fact that permeability is more affected by changes in pore pressure than confining stress, as reflected in effective stress coefficients between zero and unity. ${ }^{43}$

The observed mechanical changes are also inferred from the ultrasonic attributes. Fig. 6 shows the time evolutions of permeability and the ultrasonic velocities (Fig. 6(a)), normalized maximum acoustic amplitudes (Fig. 6(b)), and ultrasonic attenuations (Fig. 6(c)) at different levels of $P_{\text {down }}$. The ultrasonic velocities are relatively constant within each stage of effective stress and decrease between two consecutive stages as $\mathrm{P}_{\text {down }}$ increases (i.e., effective stress increases), by $<2 \%$ for $\mathrm{V}_{\mathrm{P}}$ and $\sim 5 \%$ for $V_{S}$, as also observed by Nooraeipour et al. ${ }^{42}$ In addition, the normalized maximum amplitudes decrease, and ultrasonic attenuations 

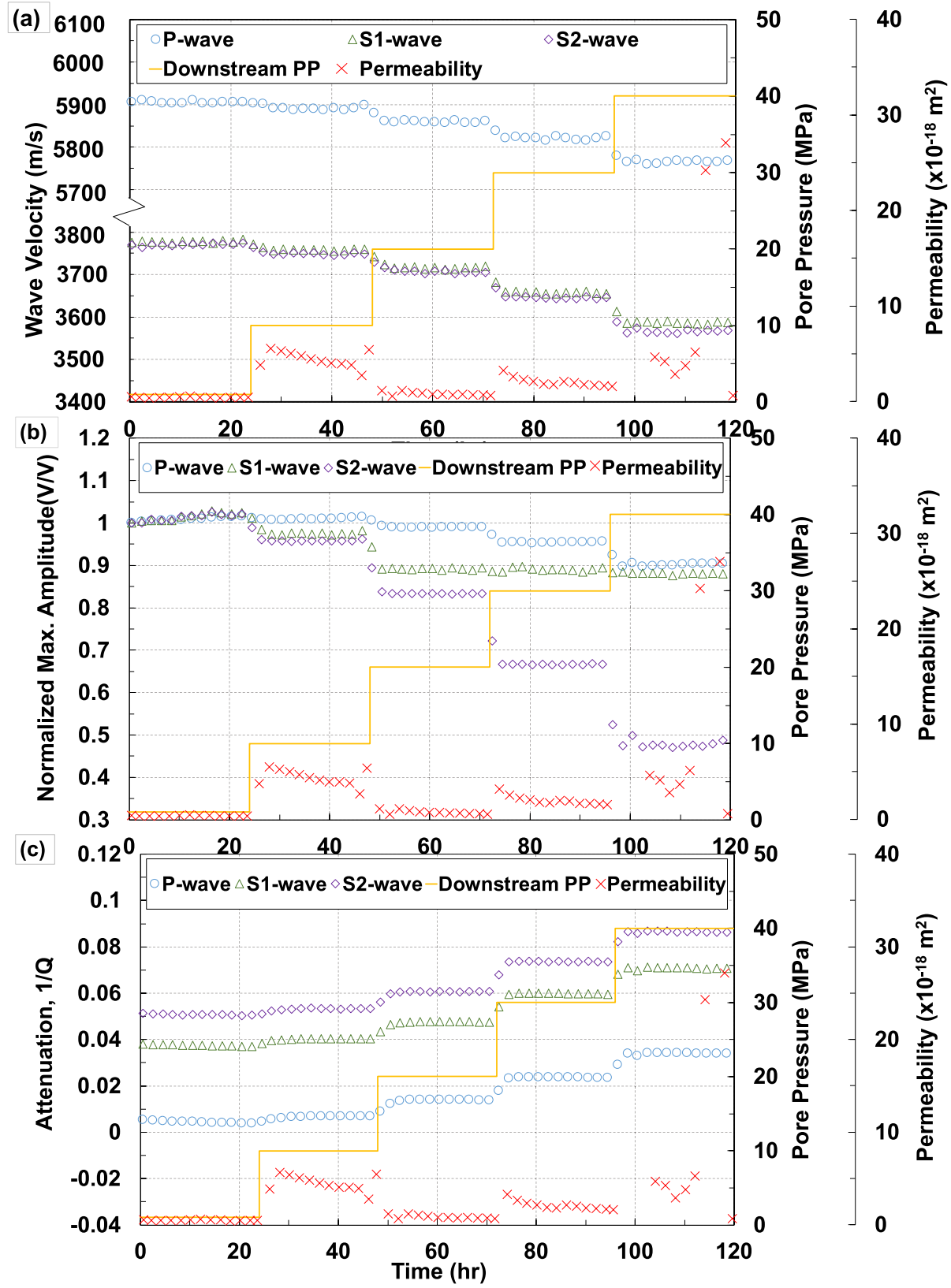

40

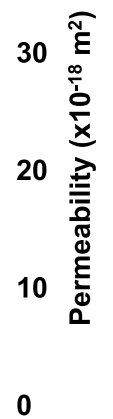

Fig. 6. Variation of ultrasonic (a) velocities, (b) maximum normalized amplitudes, and (c) attenuations for P-, $\mathrm{S}_{1}$-, and $\mathrm{S}_{2}$-waves, together with the permeability evolution during the DCT.

increase, as $\mathrm{P}_{\text {down }}$ increases. However, they both exhibit relatively constant value at each stage, similar to ultrasonic velocities. By considering the fourth stage, where $\mathrm{P}_{\text {down }}=30 \mathrm{MPa}$, the average permeability (based on Eq. (2)) and average fracture aperture (based on Eq. (3)) were estimated as $2.09 \times 10^{-18} \mathrm{~m}^{2}$ and $0.89 \mu \mathrm{m}$, respectively.

\subsection{Pressure controlled test (PCT)}

Fig. 7 shows the time evolutions of permeability and the ultrasonic velocities (Fig. 7(a)), normalized maximum acoustic amplitudes (Fig. 7 (b)), and ultrasonic attenuations (Fig. 7(c)) at different stages of this test. Similar to the DCT, all three ultrasonic signatures are relatively constant at each stage, while they are sensitive to the changes in confining/pore pressure. The slightly higher ultrasonic velocities in PL1 specimen (see Fig. 7), compared to PL2 (see Fig. 6), can be attributed to the rock anisotropy. Note that PL1 and PL2 specimens were sub-cored (from the original core) in different directions, and the ultrasonic properties of similar phyllite specimens have shown some degree of anisotropy. ${ }^{44}$ Amplitudes of S-waves show stronger effective stress dependency than P-wave. When comparing stages 1 and 5 (see Fig. 3(b); S1 and S5), the normalized maximum amplitude of P-, S1-, and S2-waves change by $6 \%$, $63 \%$, and $41 \%$, respectively. This observation evidences that S-waves amplitudes are more stress-dependent than P-wave amplitude.

\subsection{Time-frequency analysis}

\subsubsection{P-waves}

Fig. 8(a)-(d) shows that for DCT the higher frequency range (i.e., $\sim 800 \mathrm{kHz}$ ) contributes more significantly to the time-frequency partitioning than the lower frequency range (i.e. $\sim 200 \mathrm{kHz}$ ). The higher and lower ranges of frequency are associated with body and interface Pwaves, respectively. Note that the average fracture aperture in this sample is $\sim 0.89 \mu \mathrm{m}$, which is extremely small, and hence, the P-wave is primarily propagating through the rock matrix. Consequently, the rock 


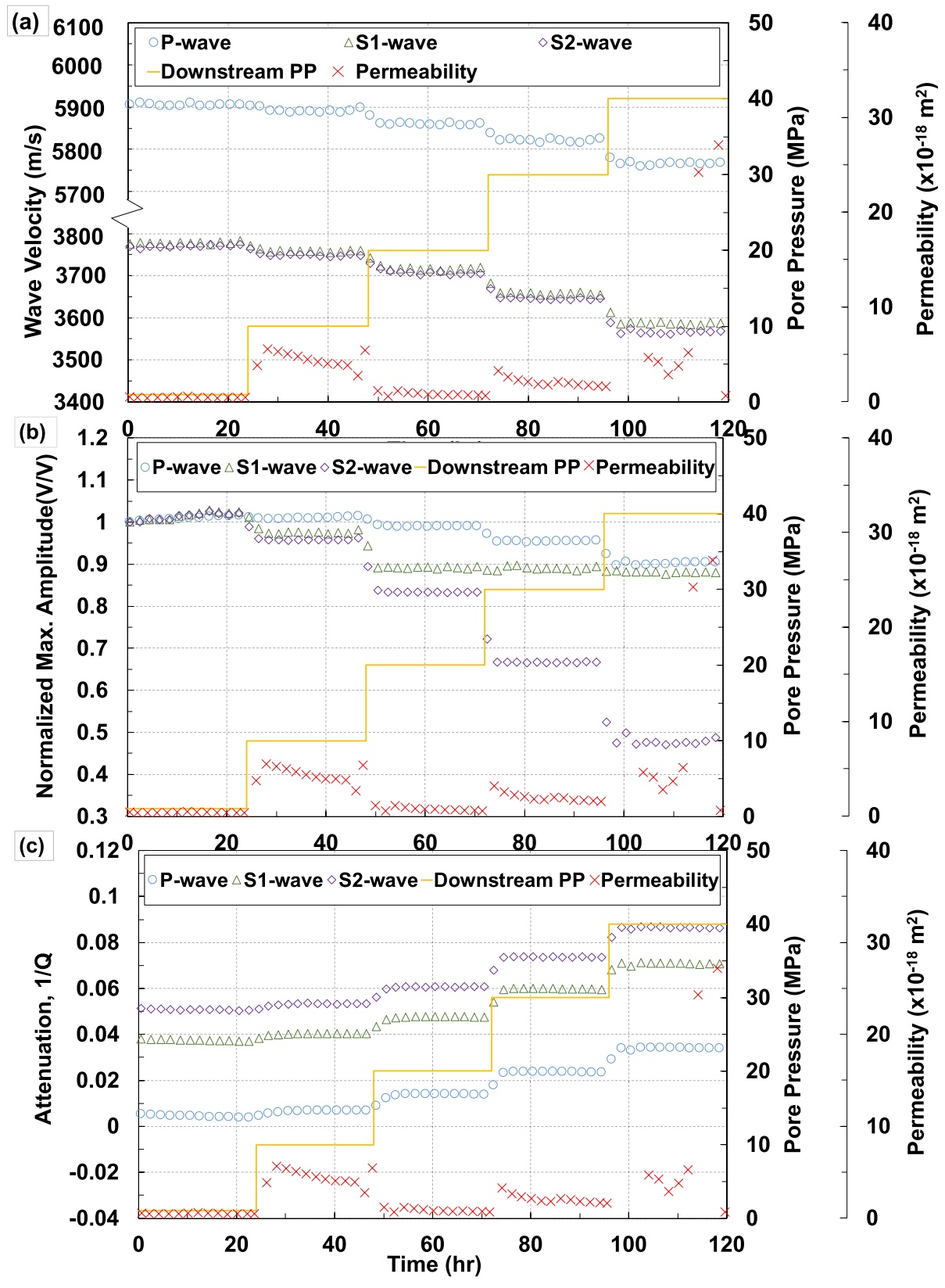

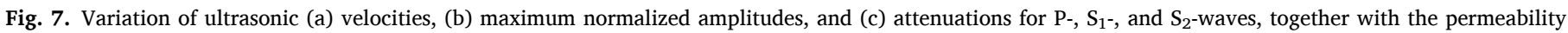
evolution during the PCT.

matrix contributes more significantly to wave propagation than the small fractured volume. As the pore pressure increases from 1 to $40 \mathrm{MPa}$ the peak amplitude of the time-frequency energy decreases by $20 \%$, indicating a positive correlation between ultrasonic wave dissipation and pore pressure. As previously mentioned, this test was performed in displacement-controlled mode, where the injection rate and the available fracture volume for fluid to flow is constant throughout the test. Subsequently, hydraulic aperture/permeability does not change over the course of the experiment. Hence, the ratio of the available volume within the fracture for fluid flow to the volume of the rock matrix is constant. Therefore, the insensitivity of frequency partitioning of timefrequency maps to the changes in the pore pressures reflects the constant hydraulic aperture (and not mechanical aperture) in the DCT. However, in the PCT (as will be discussed), in which the hydraulic aperture is variable, the frequency partitioning of time-frequency maps will be altered by the changes in pore pressure, which is attributed to the changes in hydraulic properties.
Fig. 8 (e)-(1) shows that in all the stages of the PCT, the higher frequency content of the P-wave signals $(\sim 800 \mathrm{kHz})$ arrive earlier compared to lower frequency content $(\sim 200 \mathrm{kHz})$. This phase lag reveals the energy of the P-wave signals is transmitted within the high frequency domain, as we observed in the DCT. It appears that the lower frequency part of the wavelet-transformed (hereafter referred as WT) transmitted P-waves is symmetric (fast) interface wave.

At higher effective stresses, the contribution of the higher frequency portion of the P-wave signal is more significant. This is evident by comparing Fig. 8(e) and (i), where the latter exhibits a more significant concentration of energy in the higher frequency range. This can be attributed to the fact that at higher effective stresses the fracture-specific stiffness is higher, and hence, the contribution of the body P-waves compared to the fast interface waves is more significant. ${ }^{26}$ In addition, as specific stiffness increases the upper lobe in the lower frequency range (i.e., the upper lobe of fast interface wave) tends to approach to the lower lobe. However, no significant change in the frequency partitioning 

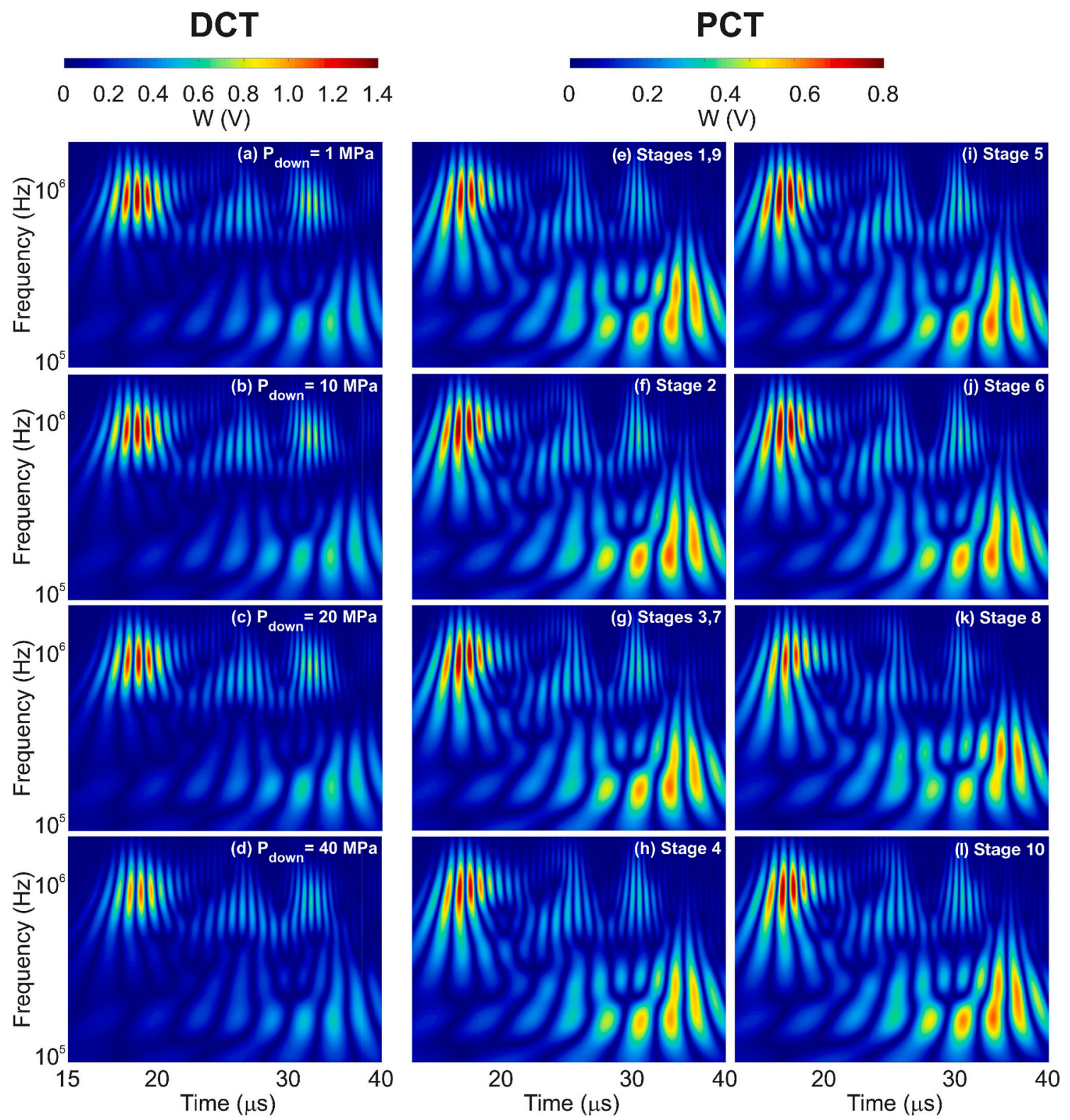

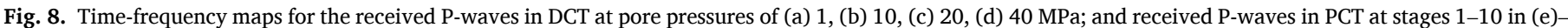

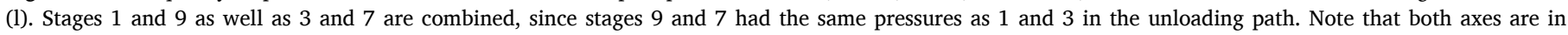
logarithmic scale.

of the higher frequency range can be observed. These two observations are consistent with the fact that the lower frequency range corresponds to fast interface wave, and in turn, alterations in flow characteristics (i. e., flow rate, asperities in contact, and fracture aperture) lead to notable changes in the time-frequency content of the fast interface waves, as it can be inferred by comparing Fig. 8(e) and (i). However, body P-waves (not interface waves) propagate through the rock matrix, and therefore, the changes in fracture-specific stiffness (caused by changes in the effective stress) do not affect body P-waves.

As evident by comparing Fig. 8(e) and (f), at higher confining pressures (while the pore pressure is constant), the amplitude of the WT transmitted wave increases. This might imply that the energy of the transmitted wave is better conserved at higher levels of effective stress. On the other hand, increase of pore pressure led to reduction in amplitude of the WT transmitted P-waves, as it can be seen by inspecting Fig. 8 (k) and (l). As pore pressure increases, the two halves of the fractured specimen get farther away and fracture aperture increases, which leads to larger fluid-filled fractured volume. Therefore, we observe a more significant energy dissipation due to interaction with higher volumes of fluid in the fracture.

\subsubsection{S-waves}

The time-frequency maps of the $S_{1}$-wave (in the DCT; Fig. 9(a)-(d)) and $S_{2}$-wave (in the PCT; Fig. 9(e)-(1)) exhibit concentration of energy around the lower frequency range (i.e., $\sim 250 \mathrm{kHz}$ ) and higher frequency range (i.e., $\sim 600 \mathrm{kHz}$ ), respectively. This difference in frequency partitioning of the two cross-polarized S-waves can be attributed to the fact that there is a $90^{\circ}$ difference in their propagation/polarization directions and the dominant wave propagation mode is interface wave for $S_{1}$-wave, while, that of $S_{2}$-wave is body wave. It should be noted that, to be concise, the time-frequency maps of $S_{2}$-waves in the DCT and $S_{1}$ waves in the PCT are not presented as their trend were found to be very similar to the time-frequency maps of $S_{1}$-waves in the DCT and $S_{2}$-waves in the PCT, respectively.

In the DCT, at higher pore pressures, the peak amplitude of WT transmitted S-waves decreases by $\sim 20 \%$, as also observed for P-waves. 

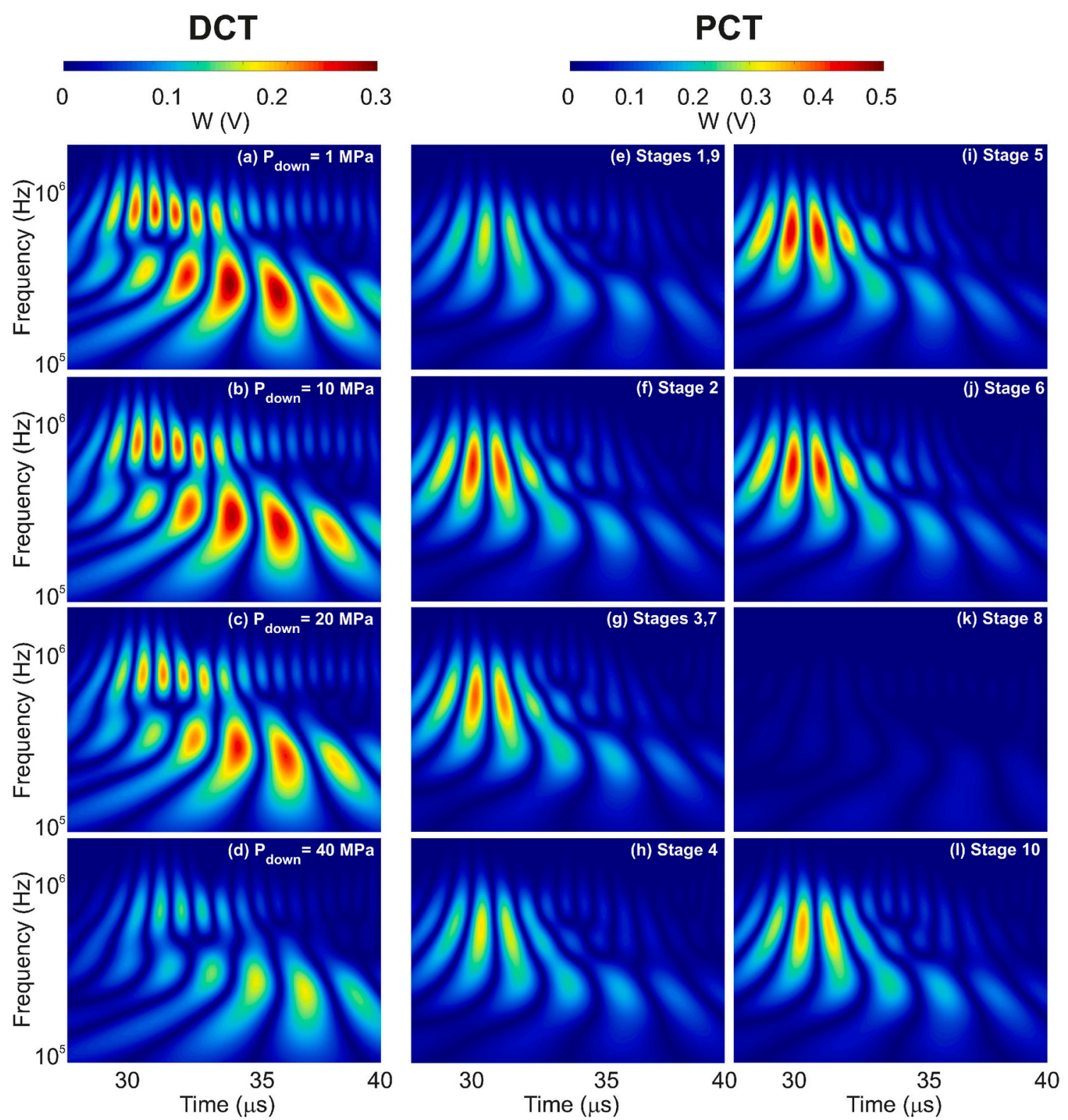

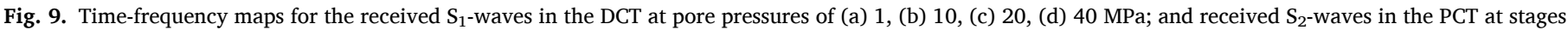

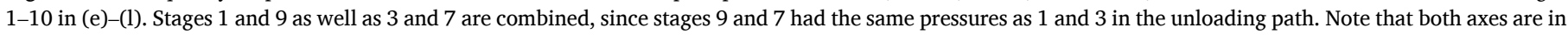
logarithmic scale.

More importantly, the frequency partitioning of S-waves remains unaltered by the variation of pore pressure. As previously explained, this can be attributed to the fact that this test was performed in displacementcontrolled mode, and hence, the available fracture volume for fluid flow is constant throughout the test. Therefore, the frequency partitioning of time-frequency maps is sensitive to the changes in hydraulic aperture but not solely pore pressure.

Fig. 9(e)-(1) shows that the peak amplitudes of the WT transmitted Swaves occur at two different frequencies during the PCT. The higher frequency range, centered at $\sim 600 \mathrm{kHz}$, corresponds to the transmitted body S-wave and the lower frequency range, centered at $\sim 250 \mathrm{kHz}$, corresponds to the transmitted slow (antisymmetric) interface wave. As fracture specific stiffness increases with the effective stress, the contribution of transmitted energy through slow interface wave becomes less significant. For example, a comparison between Fig. $9(\mathrm{~h})$, stage $4\left(\mathrm{P}_{\mathrm{c}}=\right.$ $45, \mathrm{Pp}=11 \mathrm{MPa})$, and Fig. $9(\mathrm{k})$, stage $8\left(\mathrm{P}_{\mathrm{c}}=15, \mathrm{Pp}=11 \mathrm{MPa}\right)$ reveals that when fracture-specific stiffness is high (i.e., Fig. 9(h): Stage 4), the higher frequency has a more significant contribution to energy of the transmitted signal. As also observed for P-waves, the amplitude of WT transmitted S-waves increases with fracture specific stiffness (i.e., confining pressure increases and/or pore pressure decreases). This could be attributed to the fact that at higher fracture-specific stiffness values, hydraulic aperture is lower, and therefore, the medium is less energydispersive. It was also observed by other researchers ${ }^{45}$ that an increase in fracture specific stiffness lowers the fluid flow, which in turn, is translated into lower hydraulic aperture.

\section{Discussion}

\subsection{Pressure-dependency of ultrasonic properties}

The ultrasonic properties of the fractured samples are strongly stress dependent. The imposed stress conditions targeted changes in the confining and pore pressures. The effects of increase (or decrease) in confining pressure on ultrasonic signatures are different than those caused by decrease (or increase) of pore pressure, although both of them 


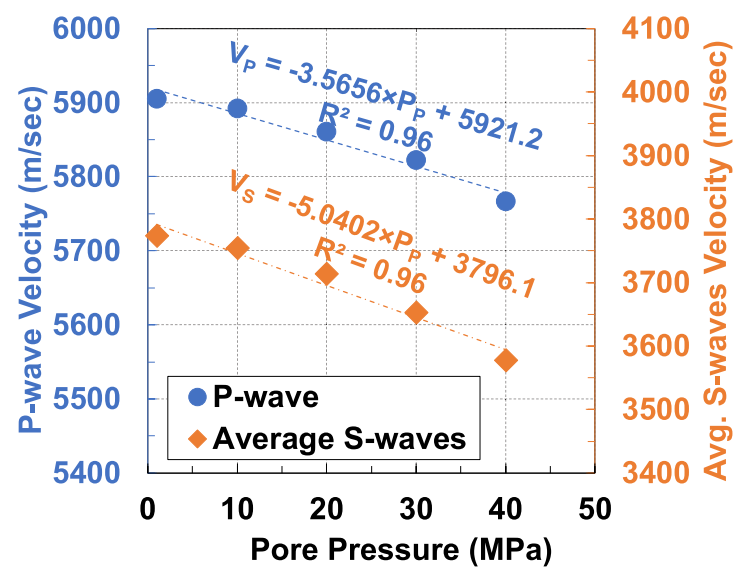

(a)

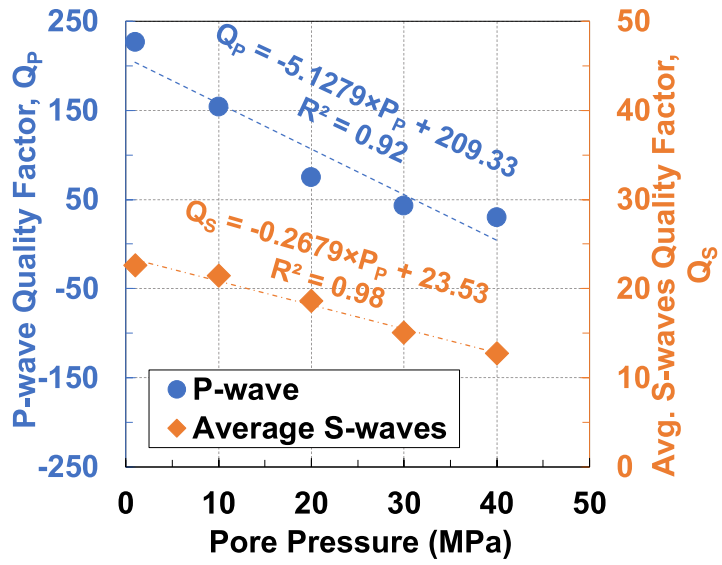

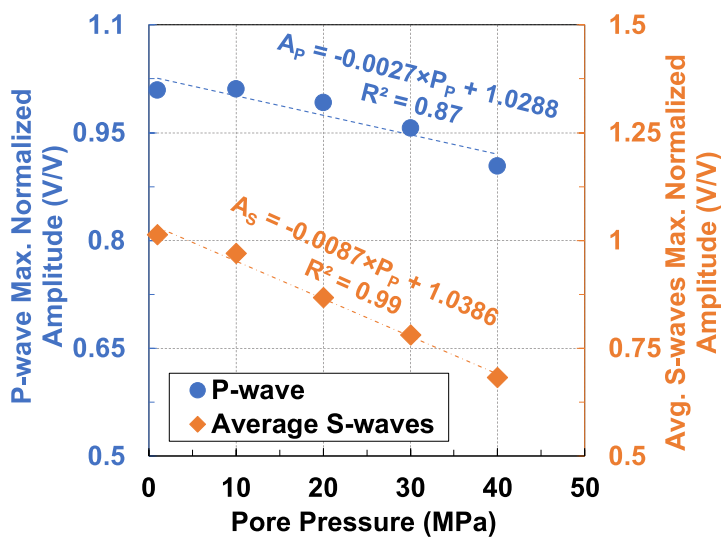

(b)

(c)

Fig. 10. Variation of average ultrasonic (a) velocities, (b) amplitudes, (c) quality factors against pore pressures in the DCT.

might lead to the same level of effective stress. For instance, consider a hypothetical scenario where the fractured specimen is subjected to confining and pore pressures of 40 and $20 \mathrm{MPa}$, respectively, which is corresponding to an effective stress of $20 \mathrm{MPa}$. Ultrasonic signatures are affected differently when confining pressure is increased from 40 to 50 $\mathrm{MPa}$, compared to a case in which pore pressure is decreased from 20 to $10 \mathrm{MPa}$. However, in both cases the effective stress increases from 20 to $30 \mathrm{MPa}$. This highlights the role of effective stress coefficient, which has been extensively studied for intact samples. ${ }^{46-48}$ But there is a lack of literature for fractured rocks. In this paper, we have not estimated this coefficient, although the role of confining pressure and pore pressures are separately studied. In sections 4.1 .1 and 4.1.2, we investigate the individual contribution of confining pressure and pore pressures to the changes in the ultrasonic characteristics.

\subsubsection{Pore pressure effects}

Fig. 10(a) shows that the ultrasonic velocities decrease linearly with pore pressure, with relatively high regression values for both $\mathrm{P}$ - and average $S$-waves $\left(R^{2} \sim 0.96\right.$ in both cases). This could be attributed to the fact that at higher pore pressures, while the hydraulic aperture is unchanged, the mechanical aperture increases. Subsequently, the contribution of the fluid-filled fractured volume on the propagation of ultrasonic waves becomes more significant, compared to that of rock matrix.

Fig. 10(b) shows a good correlation between the (normalized) amplitudes for P- and S-waves and pore pressure. Although both the P-and $\mathrm{S}$-waves attenuations decrease linearly with the pore pressure, $\mathrm{S}$-waves are more sensitive. This effect could be attributed to the nature of the torsional-wise propagation of shear waves, ${ }^{20}$ in that there are several repeated cycles of movement of particles from one solid half-space (i.e., rock matrix) to fluid and then movement from fluid to another solid half-space. However, P-wave propagates longitudinally, in which the particles do not typically change their medium. ${ }^{21,25}$

The higher the applied pore pressures, the greater the relative contribution of the fluid-filled fractured volume on wave attenuation is, and therefore, the quality factor decreases (Fig. 10(c)). The P-wave quality factor $\left(Q_{P}\right)$ shows higher sensitivity to the changes in pore pressure, compared to S-waves $\left(\mathrm{Q}_{\mathrm{S}}\right)$, as also observed in other studies. ${ }^{32}$ In addition, the range of $Q_{P}$-values lies between $\sim 40$ and $\sim 250$, while $Q_{S}$ values vary between $\sim 12$ and $\sim 23$, similar to other studies. ${ }^{49}$ The lower values of quality factor for average S-waves compared to P-wave can be attributed to the different nature of the propagation of shear waves compared to compressional waves, as explained earlier.

\subsubsection{Effects of confining pressure versus pore pressure}

Fig. 11(a) shows that as confining pressure increases, and under the same pore pressure, the wave velocities increase. For example, transitioning from $\mathrm{P}_{\mathrm{c}}=15$ to $30 \mathrm{MPa}$, the velocities of $\mathrm{P}$ - and average Swaves increase by $\sim 1.5 \%$ and $\sim 2.5 \%$, respectively. This observation could be attributed to (i) closure of fracture at higher levels of confining pressure, and (ii) closure of stress-relief induced micro-fractures. Same variations of effective stress at a constant confining pressure (i.e., the DCT conditions), led to $\sim 1.2 \%$ and $\sim 4 \%$ increase in P- and average Swave velocities, respectively. Therefore, $\mathrm{S}$-waves are more sensitive to the pore pressure than the confining pressure, while $\mathrm{P}$-waves have a similar dependency to both.

The ultrasonic velocities show some degree of hysteresis associated with unloading. The stiffening applied to the samples during the loading 


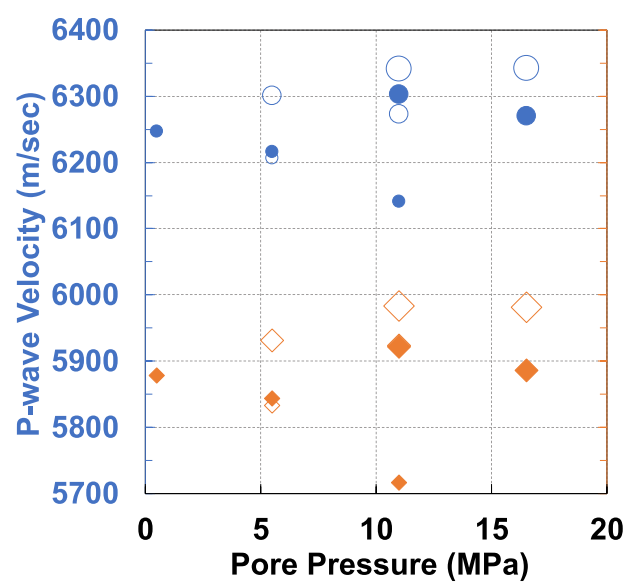

(a)

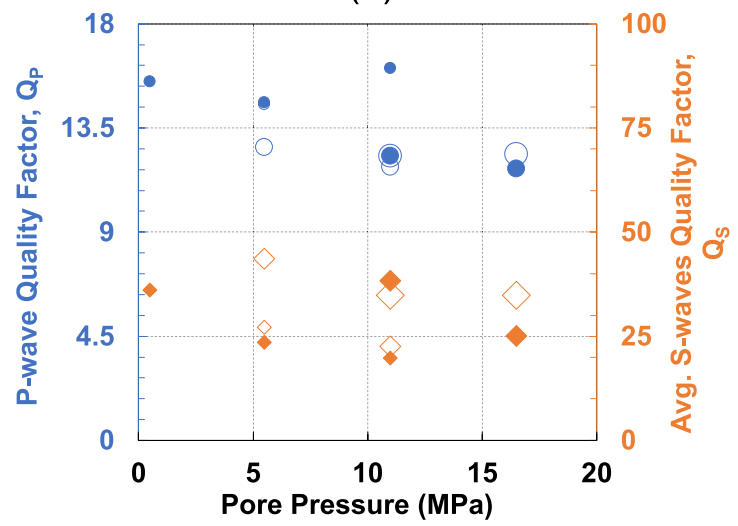

(c)

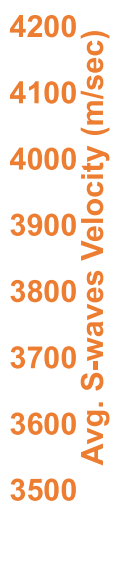

100

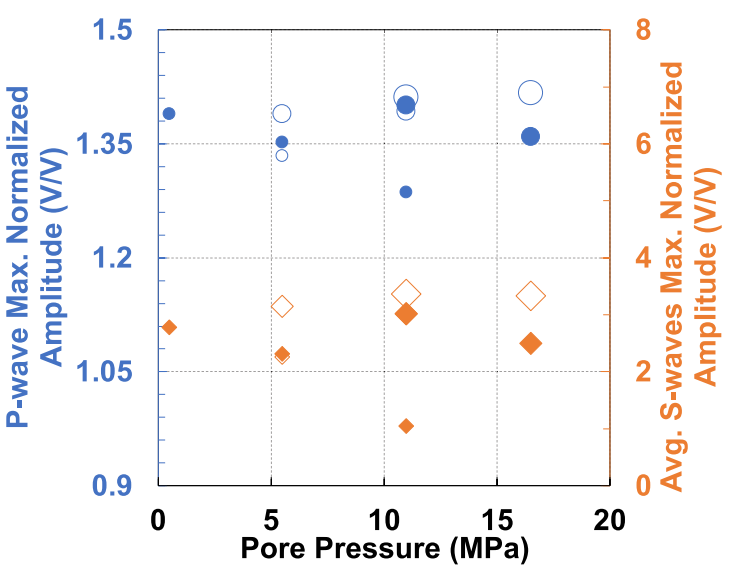

(b)

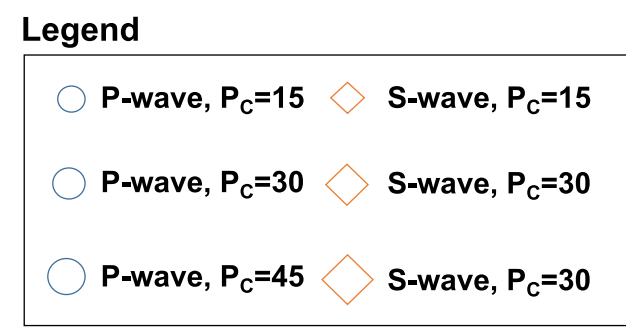

Fig. 11. Variation of average ultrasonic (a) velocities, (b) amplitudes, (c) quality factors against confining/pore pressures in the PCT. For better clarity, the horizontal axis is selected to reflect pore pressure and the size of the scatter points in the plots (circle for P-wave and diamond for average S-waves) reflect the confining pressure, with the smallest size referring to $G P P_{c}=15 \mathrm{MPa}$, the intermediate size referring to $P_{c}=30 \mathrm{MPa}$, and the biggest size referring to $P_{c}=45 \mathrm{MPa}$. It should be noted that the empty and filled scatter points (circles for P-wave and diamonds for average S-waves) reflect the loading and unloading stages, respectively.

stress path is not completely recovered during the unloading, resulting in little increases of both the $\mathrm{Vp}(\sim 0.1 \%)$ and $\mathrm{Vs}(\sim 0.3 \%)$, under the same stress states. This observation could be attributed to the fact that stress corrosion occur as higher effective stresses are applied, and irreversible changes occur in the fracture aperture, resulting in lower fracture aperture in the unloading cycle compared to the loading cycle. ${ }^{4,5}$

Fig. 11(b) shows that the maximum normalized amplitude increases for both P- and average S-waves with effective stress. For example, transitioning from $\mathrm{P}_{\mathrm{c}}=30$ to $15 \mathrm{MPa}$, the average normalized maximum $\mathrm{P}$ - and average $\mathrm{S}$-waves amplitudes decrease by $\sim 8 \%$ and $\sim 65 \%$, respectively. On the other hand, transitioning from $\mathrm{P}_{\text {down }}=11$ to 0.5 $\mathrm{MPa}$, the normalized maximum P- and S-waves amplitudes increase by $\sim 8 \%$ and $166 \%$, respectively. Effective stress has more a significant effect on the normalized maximum amplitudes of average S-waves compared to that of P-wave, as also observed in the DCT. For example, the range of the normalized maximum amplitude for P- and average $\mathrm{S}$ waves lie from 1.29 to 1.42 and 1.05 to 3.37 , respectively. As for the ultrasonic velocities, hysteresis in maximum amplitude values for both $\mathrm{P}$ - and average S-waves from loading to unloading stages suggests that the stress corrosion plays a crucial role in the stress-induced fracture response. $^{4,5}$

Fig. 11(c) shows the variation of the average ultrasonic quality factors in each stage of the PCT against pore and confining pressure. As stated above, the P-wave attenuations (or equivalently quality factors) show significant scattering. The average $S$-waves ultrasonic quality factors increase with the confining and decrease with pore pressure, as also observed for ultrasonic velocities and amplitudes. For example, from $\mathrm{P}_{\mathrm{c}}=30$ to $45 \mathrm{MPa}$, the average value of attenuation for average Swaves increase by $\sim 54 \%$. While, from $\mathrm{P}_{\text {down }}=11$ to 5.5 and then to 0.5 $\mathrm{MPa}$, the average attenuation of S-waves increases by $\sim 19 \%$ and then $\sim 82 \%$. However, comparing the loading and unloading stress paths provides no evidences of the sensitivity of ultrasonic quality factors to stress corrosion.

\subsection{Fracture-specific stiffness}

Fracture-specific stiffness is defined as the slope of the stressdisplacement curve. ${ }^{25}$ Alternatively, the ultrasonic velocities and attenuations can be implemented to calculate fracture-specific stiffness $(\kappa)$ using Eq. (4) ${ }^{50}$ :

$\kappa=\frac{\omega \rho V_{s}}{\sqrt{\frac{1}{T_{S}^{2}}-1}}$

where $\kappa$ is the fracture-specific stiffness $(\mathrm{Pa} / \mathrm{m}), \omega$ is the central frequency of the signal $(\mathrm{Hz}), \rho$ is the density of the rock specimen $\left(\mathrm{kg} / \mathrm{m}^{3}\right)$, $\mathrm{V}_{\mathrm{S}}$ is the $\mathrm{S}$-wave velocity $(\mathrm{m} / \mathrm{s})$, and $\mathrm{T}_{\mathrm{S}}$ is the unitless $\mathrm{S}$-wave transmission coefficient.

By applying Eq. (4) for the DCT data, we observe that as pore pressure increases, the fracture-specific stiffness decreases (Fig. 12(a)). At lower pore pressures (i.e., higher effective stresses), the fluid-filled fracture volume is reduced, and hence, the deformation of the fractured specimen is expected to be smaller. This could be attributed to the fact that higher effective stresses would lead to an increase in the slope 


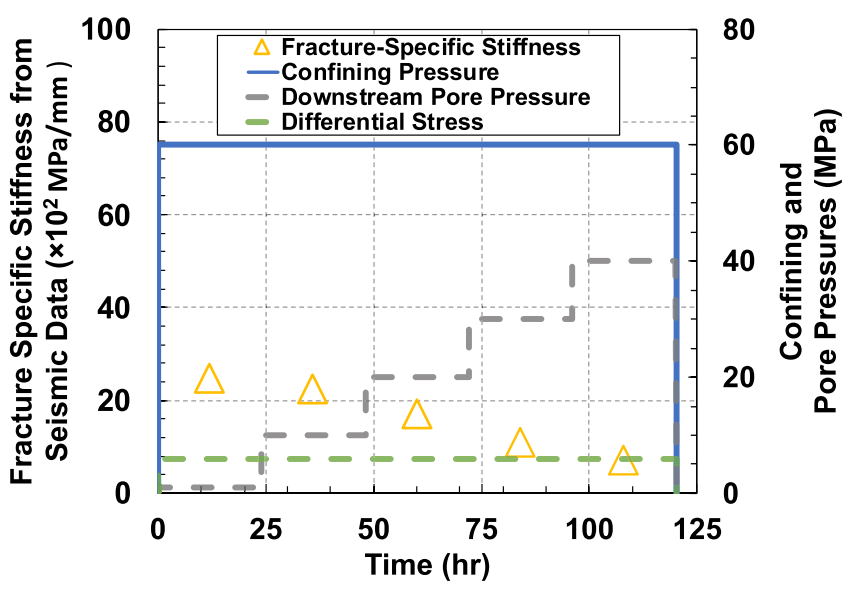

(a)

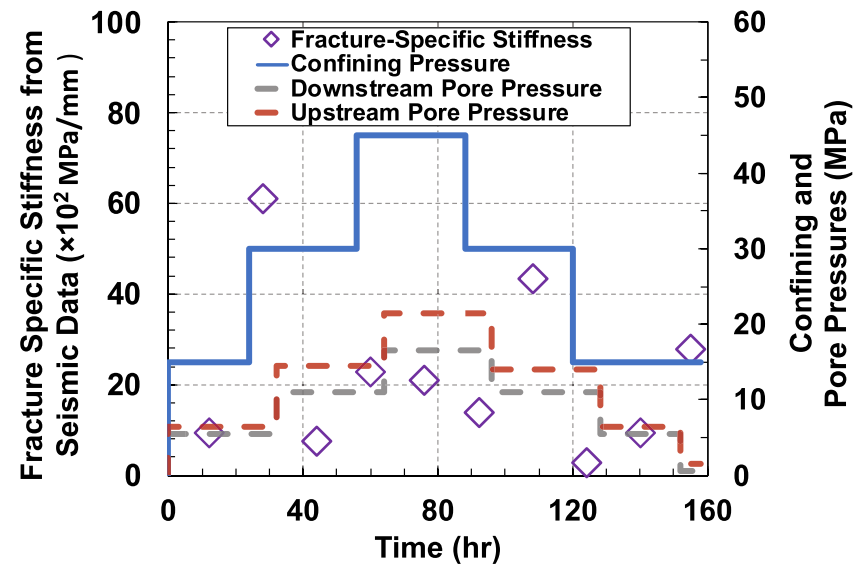

(b)

Fig. 12. Fracture-specific stiffness estimated from ultrasonic data in the (a) DCT and (b) PCT.

of the stress-displacement at the fracture interface, which in turn, increases the fracture-specific stiffness. For example, from $\mathrm{P}_{\text {down }}=20$ to $30 \mathrm{MPa}$, the fracture-specific stiffness decreases by $\sim 23 \%$.

Fig. 12(b) shows the variation of fracture-specific stiffness at different stages of the PCT, indicating higher $\kappa$ values at higher levels of effective stress (i.e., either at higher confining pressures or lower pore pressures). This is consistent with the fact that at higher effective stresses, the fracture is being closed, and hence, the fractured specimen is likely to exhibit smaller deformations. Therefore, the higher the effective stress the higher the fracture-specific stiffness is, as also observed in the DCT. The individual contribution of each the confining and pore pressure lead to similar results. For instance, transitioning from $\mathrm{P}_{\mathrm{c}}=30$ to $45 \mathrm{MPa}$ in the loading path results in $\sim 200 \%$ increase in the fracture-specific stiffness; while, transitioning from $\mathrm{P}_{\text {down }}=11$ to 5.5 $\mathrm{MPa}$ and further to $0.5 \mathrm{MPa}$, in the unloading path, leads to $\sim 200 \%$ increase in the fracture-specific stiffness.

\subsection{Time-dependent radial displacement modelling}

During the DCT, the radial strains at the fracture surface were measured and used as an additional indication that fracture is closing under constant stress states at different pore pressure levels. Two models known as Three-Element and Power-Law models ${ }^{51}$ were used to predict the longer-time fracture displacement history (perpendicular to the flow direction; see Fig. 1(c)) of the fractured sample. The Three-Element model is composed of a dashpot and a Maxwell model (a spring and a dashpot in parallel) in series configuration, as shown in Fig. 13. Eq. (5) provides the differential equation for this $\operatorname{model}^{51}$ :

$\sigma+\frac{\eta_{1}+\eta_{2}}{E} \dot{\sigma}=\eta_{1} \dot{\varepsilon}+\frac{\eta_{1} \eta_{2}}{E} \ddot{\varepsilon}$

where $\sigma$ is the applied stress, $\varepsilon$ is the time-dependent strain, $\eta_{1}$ is the dashpot coefficient, and $\left(\eta_{2}, E\right)$ are the dashpot and spring coefficients for the Maxwell unit.

Solving Eq. (5) will result in the following expression for strain as Eq. (6) ${ }^{51}$ :

$\varepsilon=\sigma\left[\frac{1}{\eta_{1}} t+\frac{1}{E}\left(1-e^{-\frac{E}{\eta_{2}} t}\right)\right]$

Power-Law model is defined as Eq. (7) ${ }^{51}$ :

$\varepsilon=\sigma \times B t^{n}$

where $\varepsilon$ is the time-dependent strain, $\sigma$ is the applied stress, and $B$ and $n$ are empirical parameters.

The experimental data (i.e., radial strains) were used to fit ThreeElement and Power-Law models and find the associated parameters, which are $\eta_{1}, \eta_{2}$, and $\mathrm{E}$ in the former case and $\mathrm{B}$ and $\mathrm{n}$ in the latter. These five parameters were estimated at pore pressures of $10,20,30$, and 40 MPa (see Table 3). In general, $B$ increases with the pore pressure, while $E, \eta_{1}, \eta_{2}$, and $n$ decrease. Fig. 14 shows the variation of radial
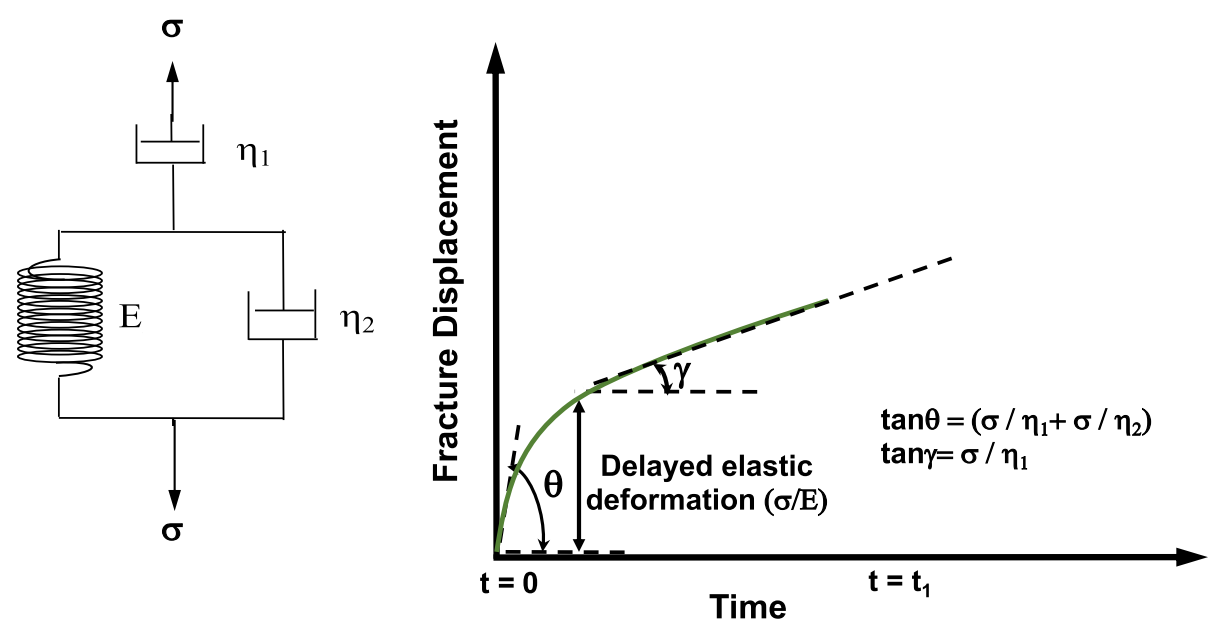

Fig. 13. Schematic of Three-Element model and the displacement at the fracture surface perpendicular to the fracture surface. 
Table 3

Parameters of three-element and power-law models.

\begin{tabular}{llllll}
\hline \multirow{2}{*}{ Model } & Parameter & \multicolumn{3}{l}{ Pore Pressure (MPa) } \\
\cline { 3 - 6 } & & 10 & 20 & 30 & 40 \\
\hline \multirow{2}{*}{ Three-Element } & $\mathrm{E}(\mathrm{GPa})$ & 1667 & 794 & 403 & 169 \\
& $\eta_{1}(\mathrm{GPa} . \mathrm{h})$ & 12535 & 10288 & 8333 & 5447 \\
& $\eta_{2}(\mathrm{GPa} . \mathrm{h})$ & 7590 & 2594 & 659 & 886 \\
Power-Law & $\mathrm{n}\left(\mathrm{MPa}^{-1}\right) \times 10^{-6}$ & 0.730 & 0.587 & 0.403 & 0.230 \\
& $\mathrm{~B}$ & -0.622 & -0.777 & -1.04 & -1.55 \\
\hline
\end{tabular}

displacement at the fracture surface obtained from experimental data against the predicted curve using Three-Element and Power-Law models. It indicates that these two models can successfully predict the time-dependent fracture displacement in flow-through experiments. It should be, however, noted that as the pore pressure increases, the accuracy of the Power-Law model in long-term prediction decreases.

\section{Conclusions}

In this paper, fluid-fracture surface interactions at variable stress states (i.e., pore and confining pressures) were investigated by conducting flow-through experiments on artificially fractured phyllite samples, retrieved from Blue Mountain geothermal field. In particular, sensitivity of $\mathrm{P}$ - and cross-polarized S-waves ultrasonic signatures (namely, velocity, amplitude, attenuation, and frequency content) and axial/radial strains under variable stress states were studied.

The results suggested that ultrasonic signatures can be potentially used as a proxy for fracture aperture alterations caused by the changes in confining and/or pore pressures. An increase in pore pressure led to the opening of the fracture, as indicated by increase in radial strains (during
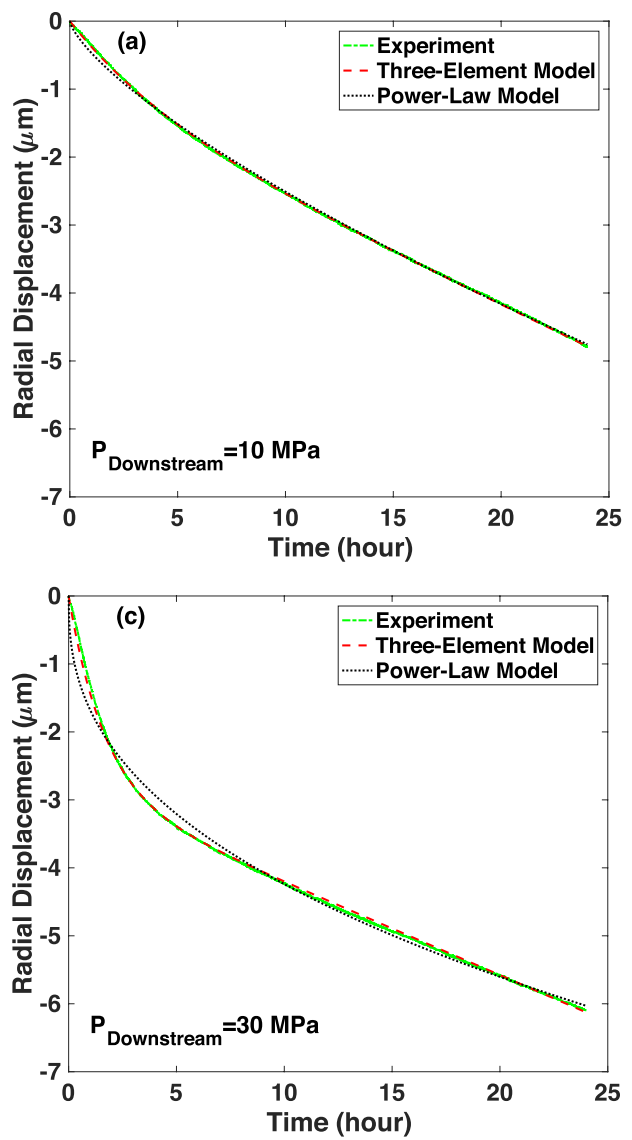

displacement-controlled test). The P-wave velocity and attenuation, and the velocity and normalized maximum amplitude of cross-polarized Swaves can be potentially used as indicators of change in fracture aperture. In particular, a decrease in fracture aperture (due to increase of confining pressure or decrease of pore pressure) led to (i) increase in the $\mathrm{P}$ - and S-wave velocities, (ii) decrease in the P-wave attenuation, and (iii) increase in the maximum amplitude of cross-polarized S-waves. However, the P-wave amplitude and S-waves attenuations exhibited less sensitivity to the changes in the fracture aperture.

The time-frequency maps of the transmitted ultrasonic P-waves revealed two distinct higher and lower frequency bands of $\sim 800$ and $\sim 200 \mathrm{kHz}$, while both S-waves revealed a higher and lower frequencies of $\sim 650$ and $\sim 250 \mathrm{kHz}$, respectively. The higher frequency bands (in both cases) correspond to the body waves, while the lower bands correspond to the fast interface waves (in case of P-wave) and slow interface waves (in case of S-waves). Frequency partitioning of the timefrequency maps is sensitive to the changes in hydraulic aperture as the frequency partitioning is unchanged in displacement-controlled test with constant hydraulic aperture. However, in pressure-controlled test, where the hydraulic aperture is not constant throughout the experiment, the frequency partitioning is altered. At higher fracture-specific stiffness values (i.e., higher confining pressures or lower pore pressures), the body waves substantially contribute to the transmitted wave, while at lower fracture-specific stiffness values (i.e., lower confining pressures or higher pore pressures), the interface waves exhibit an enhanced contribution to the response.

Closure of fracture at a constant level of confining and pore pressures led to reduction in the permeability of the fractured rock. Three-Element and Power-Law models were used to predict the longer-term behavior of chemo-mechanical creep (i.e., radial displacement at the fracture surface) in flow-through experiments under constant pressures during
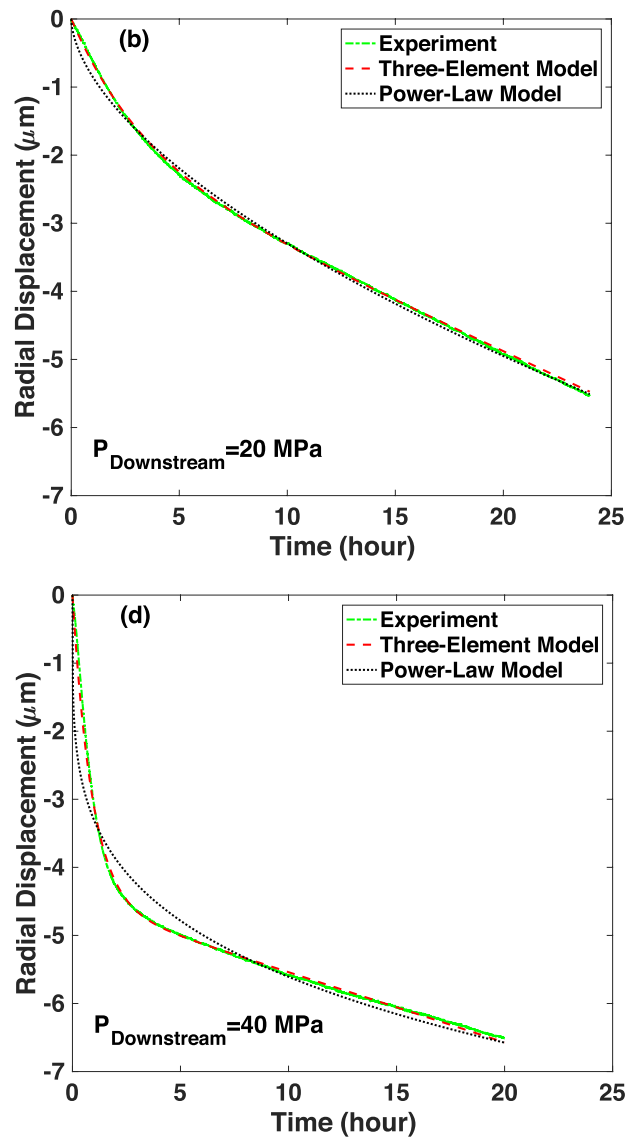

Fig. 14. Modelling time-dependent fracture displacement at each stage of the DCT using Three Element and Power-Law models for $P_{\text {down }}$ of (a) 10, (b) 20 , (c) 30 , and (d) $40 \mathrm{MPa}$. 
displacement-controlled test. It was found that both of these models can successfully predict the radial displacement at the fracture surface, with a reduced accuracy for the Power-Law model at higher pore pressures.

\section{Declaration of competing interest}

The authors declare that they have no known competing financial interests or personal relationships that could have appeared to influence the work reported in this paper.

\section{Acknowledgments}

This research did not receive any specific grant from funding agencies in the public, commercial, or not-for-profit sectors. The authors are very thankful to AltaRock Energy Inc. and University of Nevada, Reno for providing the phyllite rock core used in this study. We also wish to thank feedback from Professor Ahmadreza Hedayat at Colorado School of Mines and geophysical research team at New England Research Inc.

\section{References}

1 Lorenz JC, Cooper SP. Applied Concepts in Fractured Reservoirs. Hoboken, NJ: John Wiley \& Sons; 2020.

2 Ghassemi A. A review of some rock mechanics issues in geothermal reservoir development. Geotech Geol Eng. 2012;30(3):647-664.

3 KC B, Foroutan M, Kamali-Asl A, Ghazanfari E, Cladouhos TT. Geomechanical characterization of a granodiorite rock specimen from Patua geothermal field. In: 53rd US Rock Mechanics/geomechanics Symposium. New York City; 23-26 June; 2019.

4 Yasuhara H, Elsworth D. Compaction of a rock fracture moderated by competing roles of stress corrosion and pressure solution. Pure Appl Geophys. 2008;165(7): 1289-1306.

5 Kamali-Asl A, Ghazanfari E, Perdrial N, Bredice N. Experimental study of fracture response in granite specimens subjected to hydrothermal conditions relevant for enhanced geothermal systems. Geothermics. 2018;72:205-224.

6 Bächler D, Kohl T. Coupled thermal-hydraulic-chemical modelling of enhanced geothermal systems. Geophys J Int. 2005;161(2):533-548.

7 Kamali-Asl A, Ghazanfari E, Perdrial N, Cladouhos T. Effects of injection fluid type on pressure-dependent permeability evolution of fractured rocks in geothermal reservoirs: an experimental chemo-mechanical study. Geothermics. 2020;87:101832.

8 Sone H, Zoback MD. Time-dependent deformation of shale gas reservoir rocks and its long-term effect on the in situ state of stress. Int J Rock Mech Min Sci. 2014;69: 120-132.

9 Bažant ZP, Salviato M, Chau VT, Viswanathan H, Zubelewicz A. Why fracking works. J Appl Mech. 2014;81(10):101010.

10 McClure MW, Horne RN. An investigation of stimulation mechanisms in enhanced geothermal systems. Int J Rock Mech Min Sci. 2014;72:242-260.

11 Caulk RA, Ghazanfari E, Perdrial JN, Perdrial N. Experimental investigation of fracture aperture and permeability change within enhanced geothermal systems. Geothermics. 2016;62:12-21.

12 Hakso A, Zoback MD. The relation between stimulated shear fractures and production in the Barnett Shale: implications for unconventional oil and gas reservoirs. Geophysics. 2019;84(6):B461-B469.

13 Kamali-Asl A, Ghazanfari E, Hedayat A, Deering L. Investigation of static/dynamic moduli and plastic response of shale specimens. Int J Rock Mech Min Sci. 2018;110: 231-245.

14 Zoback MD, Kohli AH. Unconventional Reservoir Geomechanics. Cambridge, UK: Cambridge University Press; 2019.

15 Kamali-Asl A, Ghazanfari E, Newell P, Stevens M. Elastic, viscoelastic, and strength properties of Marcellus Shale specimens. J Petrol Sci Eng. 2018;171:662-679.

16 Pyrak-Nolte LJ, Nolte DD. Approaching a universal scaling relationship between fracture stiffness and fluid flow. Nat Commun. 2016;7:10663.

17 Mavko G, Mukerji T, Dvorkin J. The Rock Physics Handbook: Tools for Seismic Analysis of Porous Media. Cambridge, UK: Cambridge University Press; 2009.

18 Yang H, Duan HF, Zhu J. Effects of filling fluid type and composition and joint orientation on acoustic wave propagation across individual fluid-filled rock joints. Int J Rock Mech Min Sci. 2020;128:104248.

19 Yang H, Duan HF, Zhu JB. Thermal effect on compressional wave propagation across fluid-filled rock joints. Rock Mech Rock Eng. 2020:1-8.

20 Biot MA. Theory of propagation of elastic waves in a fluid-saturated porous solid. I. Low-frequency range. J Acoust Soc Am. 1956;28(2):168-178.
21 Pyrak-Nolte LJ, Myer LR, Cook NG. Transmission of seismic waves across single natural fractures. J Geophys Res. 1990;95(B6):8617-8638.

22 Delle Piane C, Sarout J, Madonna C, Saenger EH, Dewhurst DN, Raven MD. Frequency-dependent seismic attenuation in shales: experimental results and theoretical analysis. Geophys J Int. 2014;198(1):504-515.

$23 \mathrm{Xu}$ PC, Parra JO. Effects of single vertical fluid-filled fractures on full waveform dipole sonic logs. Geophysics. 2003;68(2):487-496.

24 Yang H, Duan HF, Zhu JB. Ultrasonic P-wave propagation through water-filled rock joint: an experimental investigation. J Appl Geophys. 2019;169:1-14.

25 Cook NG. Natural joints in rock: mechanical, hydraulic and seismic behaviour and properties under normal stress. Int J Rock Mech Min Sci. 1992;29(3):198-223.

26 Roy S, Pyrak-Nolte LJ. Interface waves propagating along tensile fractures in dolomite. Geophys Res Lett. 1995;22(20):2773-2776.

27 Brajanovski M, Müller TM, Gurevich B. Characteristic frequencies of seismic attenuation due to wave-induced fluid flow in fractured porous media. Geophys J Int. 2006;166(2):574-578.

28 Trimmer D, Bonner B, Heard HC, Duba A. Effect of pressure and stress on water transport in intact and fractured gabbro and granite. J Geophys Res: Solid Earth. 1980; 85(B12):7059-7071.

29 Yu Y, Zhang J, Zhang J. A modified Brazilian disk tension test. Int J Rock Mech Min Sci. 2009;46(2):421-425.

30 Falcon-Suarez I, Marín-Moreno H, Browning F, et al. Experimental assessment of pore fluid distribution and geomechanical changes in saline sandstone reservoirs during and after CO2 injection. Int. J. Greenh. Gas Con. 2017;63:356-369.

31 Standard ASTMD5777-00. Standard Guide for Using the Seismic Refraction Method for Subsurface Investigation. West Conshohocken, PA: ASTM International; 2011.

32 Kamali-Asl A, KC B, Ghazanfari E, Hedayat A. Flow-induced alterations of ultrasonic signatures and fracture aperture under constant state of stress in a single-fractured rock. Geophysics. 2019;84(4):WA115-W125.

33 Daubechies I. The wavelet transform, time-frequency localization and signal analysis. IEEE Trans Inf Theor. 1990;36(5):961-1005.

34 Torrence C, Compo GP. A practical guide to wavelet analysis. Bull Am Meteorol Soc. 1998;79(1):61-78.

35 Farzampour A, Kamali-Asl A, Hu JW. Unsupervised identification of arbitrarilydamped structures using time-scale independent component analysis: Part I. J Mech Sci Technol. 2018;32(2):567-577.

36 Farzampour A, Kamali-Asl A, Hu JW. Unsupervised identification of arbitrarilydamped structures using time-scale independent component analysis: Part II. J Mech Sci Technol. 2018;32(9):4413-4422.

37 Kumar P, Foufoula-Georgiou E. Wavelet analysis for geophysical applications. Rev Geophys. 1997;35(4):385-412.

38 Witherspoon PA, Wang JS, Iwai K, Gale JE. Validity of cubic law for fluid flow in a deformable rock fracture. Water Resour Res. 1980;16(6):1016-1024.

39 Renshaw CE. On the relationship between mechanical and hydraulic apertures in rough-walled fractures. J Geophys Res: Solid Earth. 1995;100(B12):24629-24636.

40 Lee HS, Cho TF. Hydraulic characteristics of rough fractures in linear flow under normal and shear load. Rock Mech Rock Eng. 2002;35(4):299-318.

41 Atkinson BK. A fracture mechanics study of subcritical tensile cracking of quartz in wet environments. Pure Appl Geophys. 1979;117(5):1011-1024.

42 Nooraiepour M, Bohloli B, Park J, Sauvin G, Skurtveit E, Mondol NH. Effect of brine$\mathrm{CO} 2$ fracture flow on velocity and electrical resistivity of naturally fractured tight sandstones. Geophysics. 2018;83(1):WA37-48.

43 Al-Wardy W, Zimmerman RW. Effective stress law for the permeability of clay-rich sandstones. J. Geophys. Res. Solid Earth. 2004;109(B4):B04203.

44 Kamali-Asl A, KC B, Foroutan M, Ghazanfari E, Cladouhos TT, Stevens M. Stressstrain response and seismic signature analysis of phyllite reservoir rocks from Blue Mountain geothermal field. Geothermics. 2019;77:204-223.

45 Pyrak-Nolte LJ, Morris JP. Single fractures under normal stress: the relation between fracture specific stiffness and fluid flow. Int J Rock Mech Min Sci. 2000;37(1-2): 245-262.

46 Todd T, Simmons G. Effect of pore pressure on the velocity of compressional waves in low-porosity rocks. J. Geophys. Res. Solid Earth. 1972;77(20):3731-3743.

47 Ma X, Zoback MD. Laboratory experiments simulating poroelastic stress changes associated with depletion and injection in low-porosity sedimentary rocks. J. Geophys. Res. Solid Earth. 2017;122(4):2478-2503.

48 Falcon-Suarez IH, North L, Callow B, Bayrakci G, Bull J, Best A. Experimental assessment of the stress-sensitivity of combined elastic and electrical anisotropy in shallow reservoir sandstones. Geophysics. 2020;85(5):MR271-M283.

49 Amalokwu KI. Saturation Effects on Frequency-dependent Seismic Anisotropy in Fractured Porous Rocks. Southampston, UK: University of Southampton; 2016. PhD Thesis.

50 Choi MK, Bobet A, Pyrak-Nolte LJ. The effect of surface roughness and mixed-mode loading on the stiffness ratio $\mathrm{K}$ x/ $\mathrm{k} \mathrm{z}$ for fractures. Geophysics. 2014;79(5): D319-D331.

51 Zoback MD. Reservoir Geomechanics. Cambridge, UK: Cambridge University Press; 2010. 